\title{
Child Mortality and Fertility Decline: Does the Barro-Becker Model Fit the Facts?*
}

\author{
Matthias Doepke \\ UCLA
}

April 2004

\begin{abstract}
I compare the predictions of three variants of the altruistic parent model of Barro and Becker for the relationship between child mortality and fertility. In the baseline model fertility choice is continuous, and there is no uncertainty over the number of surviving children. The baseline model is contrasted to an extension with discrete fertility choice and stochastic mortality and a setup with sequential fertility choice. The quantitative predictions of the models are remarkably similar. While in each model the total fertility rate falls as child mortality declines, the number of surviving children increases. The results suggest that factors other than declining infant and child mortality are responsible for the large decline in net reproduction rates observed in industrialized countries over the last century.
\end{abstract}

JEL Classification: J13

Keywords: Child Mortality, Fertility Decline, Sequential Fertility Choice

\footnotetext{
*Financial support by the National Science Foundation (grant SES-0217051) and the UCLA Academic Senate is gratefully acknowledged. I thank Sebnem Kalemli-Oczan, Rodrigo Soares, and two anonymous referees for comments that helped to substantially improve the paper. Olesya Baker and Ilya Berger provided excellent research assistance. Department of Economics, University of California, Los Angeles, 405 Hilgard Ave, Los Angeles, CA 90095-1477, e-mail: doepke@econ.ucla.edu, fax: (801) 469-6100.
} 


\section{Introduction}

In 1861, the average woman in England had five children over her lifetime. However, only 70 percent of newborn children would live to see their tenth birthday. By 1951, average fertility had fallen to just over two children per woman, and only five percent of children would die in their first ten years of life. A similar pattern of declining fertility and mortality rates, collectively known as the demographic transition, has been observed in every industrializing country. Recently, a number of economists have developed macroeconomic theories that integrate an account of the demographic transition with theories of long-run economic growth. However, in most cases these studies have concentrated on the fertility aspect of the demographic transition, while abstracting from mortality decline (see, for example, Galor and Weil 2000 and Greenwood and Seshadri 2002). Demographers, in contrast, have pointed out that in many countries mortality decline preceded fertility decline, which suggests a causal link from falling mortality to falling fertility.

One reason why the macroeconomic literature has abstracted from mortality decline as a cause for fertility decline is that commonly used economic models of fertility choice are inconsistent with such a link. In particular, this is true for the model of Barro and Becker (1989), where parents are altruistic towards their surviving children. In the Barro-Becker model, infant and child mortality rates affect choices only to the degree that they influence the overall cost of a surviving child. Falling mortality rates lower the cost of having a surviving child, hence net fertility ${ }^{1}$ actually increases, not decreases, as mortality declines (this is discussed in Boldrin and Jones 2002 and Fernández-Villaverde 2001). The effects of falling adult mortality are more ambiguous (see Boucekkine, de la Croix, and Licandro 2002), but changing adult mortality is an unattractive explanation for fertility decline for other reasons. Most gains in adult survival rates are not closely associated with the timing of fertility decline, and most of overall mortality decline occurs at the levels of infant and child mortality. Instead of emphasizing mortality decline, the Barro-Becker framework points to the quantityquality tradeoff as an explanation for fertility decline: parents choose to have smaller families in order to invest more in the education of each child.

\footnotetext{
${ }^{1}$ Throughout the paper, the number of births per woman will be referred to as the total fertility rate, while the number of surviving children is the net fertility rate.
} 
In this paper, I examine whether simple extensions of the Barro-Becker model can overturn its predictions for the link of child mortality and fertility. In the baseline Barro-Becker model, fertility is treated as a continuous choice, all fertility decisions are made at one point in time, and there is no uncertainty over the number of surviving children. Richer models that allow for uncertainty and sequential fertility choice may lead to different implications. In particular, when mortality is stochastic and parents want to avoid the possibility of ending up with very few (or zero) surviving children, a precautionary demand for children arises. Such an increase in fertility in response to expected future child mortality is also known as the "hoarding" effect. Sah (1991) and Kalemli-Ozcan (2003) argue that when hoarding is taken into account, declining child mortality can have a strong negative impact on fertility. ${ }^{2}$ If fertility is chosen sequentially, there is also a "replacement" effect: parents may condition their fertility decisions on the survival of children that were born previously. Fertility models with stochastic outcomes and sequential choices have been used in the empirical fertility literature, see Wolpin (1997), but their theoretical and quantitative implications within the Barro-Becker framework have not yet been examined.

To analyze whether stochastic outcomes and sequential fertility choice are quantitatively important, I examine three extensions of the basic Barro-Becker framework. The first model allows for different costs per birth and per surviving child, but is otherwise identical to the Barro-Becker setup. In the second model, fertility choice is restricted to be an integer, and there is mortality risk. The third extension adds sequential fertility choice. The three models are compared with regards to their theoretical and quantitative implications regarding the link between infant and child mortality and fertility.

The main conclusion is twofold: all three models are consistent with a falling total fertility rate in response to declining child mortality, but none of the models predicts that the net fertility rate declines. In the data, in most countries both total and net fertility decline substantially during the demographic transition. In the English example, the total fertility rate fell from 4.9 in 1861 to 2.1 in 1951, while net fertility rate (the average number of children per woman surviving at least to age 5) declined from 3.6 to 2.0. Given these observations, our analysis suggests that lower child mortality

\footnotetext{
${ }^{2}$ In fact, in an earlier paper Kalemli-Ozcan (2002) develops a model that explains the entire fertility decline during the demographic transition through declining child mortality alone.
} 
did contribute to the decline of the total fertility rates, but that other factors must be behind the decline in net fertility.

To gain some intuition for these results, once again it is useful to distinguish between the hoarding and replacement responses to child mortality. Replacement behavior alone is sufficient to generate a positive relationship between child mortality and total fertility. Consider, as a simple example, a parent who wants to implement a certain target in terms of the desired number of surviving children. If fertility choice is sequential, the parent can implement this target precisely by having a sufficient number of births until the target is reached and adding another birth each time a child dies. The number of surviving children is always equal to the target, and therefore independent of mortality rates. The total fertility rate, on the other hand, is positively related to mortality: the more deaths occur, the more "replacement" births are going to take place. If child mortality declines, fewer children need to be replaced, so that the total fertility rate declines as well.

For mortality decline to have a negative effect on net fertility, the hoarding motive has to be present. That is, instead of just retroactively replacing children that died, parents would have to raise their fertility level in advance as an insurance mechanism against the future death of some of their children. A decline in child mortality will translate into a decline in net fertility only if the hoarding motive is sufficiently strong. We will see that, theoretically, such a response can indeed arise if it is impossible to replace dying children, and if parents are extremely risk averse with regards to to the possibility of having too few surviving children. The hoarding motive is counteracted, however, by risk aversion with respect to consumption and by the possibility of sequential fertility choice. We will show below that once sequential fertility choice is allowed for, hoarding behavior does not arise even if parents are highly risk averse.

The following section introduces the three models that form the basis of the analysis. Section 3 theoretically analyzes the link between child mortality and fertility in these models. The theoretical results are complemented in Section 4 with quantitative findings from a calibrated model, and a sensitivity analysis is carried out in Section 5. In Section 6, the results are contrasted to the empirical literature on the fertility-mortality link. An extension of the model that introduces endogenous education decisions is presented in Section 7. Section 8 concludes. 


\section{Three Variations on Altruistic Parents and Fertility}

As the benchmark case, I consider the model by Barro and Becker (1989) with continuous fertility choice and separate costs per birth and per surviving child. In this model, parents care about their own consumption $c$ as well as the number $n$ and utility $V$ of their surviving children. ${ }^{3}$ The utility function is:

$$
U(c, n)=\frac{c^{1-\sigma}}{1-\sigma}+\beta n^{\epsilon} V .
$$

Throughout the paper, it is assumed that $\sigma, \beta, \epsilon \in(0,1)$ and $V>0$. The deterministic model can be extended to risk-aversion parameters equal to one (log utility) or bigger than one. However, in those cases the utility associated with having zero children is negative infinity, so that the choice problem under uncertainty (where zero surviving children occur with positive probability) is not well defined. I therefore concentrate on the case $0<\sigma<1$.

Let $b$ denote the number of births, and $s$ is the probability of survival for each child, where $0<s \leq 1$. Mortality is deterministic in the sense that $s$ is the fraction of children surviving. Consequently, the number of surviving children is not constrained to be an integer. The full income of a parent is denoted by $w$. Since $w$ is taken as given, the distinction between time and goods costs for children is irrelevant. It is assumed that each birth is associated with a cost of $p$, and each surviving child entails an additional cost of $q$. The budget constraint is then $c+p b+q n \leq w$ or, after plugging in the survival function $n=s b$ :

$$
c+(p+q s) b \leq w .
$$

Income and cost parameters satisfy $w>0, p \geq 0, q \geq 0$, and $p+q>0$. At least one of the costs has to be strictly positive; otherwise, the optimal fertility choice is infinity. Both consumption and fertility are restricted to be nonnegative. The decision problem in the standard version of the Barro-Becker model is:

\footnotetext{
${ }^{3}$ If parents can choose education, $V$ becomes an endogenous variable. Since mortality is concentrated in the first few years of life, while education occurs later, there is no direct interaction between child mortality and education decisions. Therefore, I abstract from education for now; endogenous education decisions are introduced as an extension in Section 7.
} 
Model A: (Barro-Becker with continuous fertility choice)

$$
\max _{0 \leq b \leq w /(p+q s)}\left\{\frac{(w-(p+q s) b)^{1-\sigma}}{1-\sigma}+\beta(s b)^{\epsilon} V\right\}
$$

I will now consider two further variations of the Barro-Becker framework which add realism to the benchmark model. The first extension introduces stochastic survival and restricts fertility choice to be an integer. In this model, the realized number of children is uncertain. I assume that for each birth there is a constant probability of death, implying that that the distribution of surviving children is Binomial. Apart from the integer restriction and stochastic survival, the model is identical to the benchmark. The decision problem is now given by:

Model B: (Stochastic Barro-Becker with discrete fertility choice)

$$
\max _{b \in\{\mathcal{N} \cup 0\}, b \leq w /(p+q)}\left\{\sum_{n=0}^{b}\left(\frac{(w-p b-q n)^{1-\sigma}}{1-\sigma}+\beta n^{\epsilon} V\right)\left(\begin{array}{l}
b \\
n
\end{array}\right) s^{n}(1-s)^{b-n}\right\} .
$$

The second extension adds yet more realism by allowing sequential fertility choice, while preserving the integer constraint and stochastic survival of Problem B. In the sequential model, the period is divided into $T+1$ subperiods, running from 0 to $T$. Parents have a fixed income of $w$ in each subperiod. The parameter $\gamma \in(0,1)$ is the discount factor between periods. In each period, parents can give birth to a single child. Since children live for multiple periods, the setup allows to distinguish infant and child mortality. Newborn infants survive with probability $s_{i}$ until the next period. If the child survives, the probability of surviving the second period of life is $s_{y}$. Once a child has survived for two periods, it will survive until adulthood for sure. ${ }^{4} b_{t} \in\{0,1\}$ denotes the birth decision in period $t, y_{t} \in\{0,1\}$ represents a young child (born in the preceding period), and $n_{t}$ is the number of older children (born at least two periods prior) alive in period $t$. The cost per birth $b_{t}$ is given by $p$, a young child $y_{t}$ is associated with cost $q$, and older children $n_{t}$ do not involve further expenses. ${ }^{5}$ The budget constraint in period $t$ is $c_{t}+p b_{t}+q y_{t} \leq w$.

\footnotetext{
${ }^{4}$ The model could be extended to allow for a richer set of age-specific survival probabilities, but two survival probabilities are sufficient to contrast the sequential setup to the case of simultaneous fertility choice. In the data, mortality is highly concentrated in the first few years of a child's life.

${ }^{5}$ This assumption can be justified through the economic benefits of older children in terms of child
} 
In the sequential model, parents are able to decide on fertility conditional on the survival of older children. Formally, the choice object of the parent is a sequence of decision rules $\left\{b_{t}: H_{t} \rightarrow\{0,1\}\right\}_{t=0}^{T}$ which map the state $h_{t}$ at time $t$ into a birth decision. The state at time $t$ is given by $h_{t}=\left\{n_{t}, y_{t}\right\}$, where $n_{t} \geq 0$ is the number of children that were born at least two periods ago and survived, and $y_{t} \in\{0,1\}$ denotes whether there is a young child that was born in the preceding period. Since there is at most one birth per period, the maximum number of children is $K$. The state space is therefore $H_{t}=\{0,1, \ldots, K\} \times\{0,1\}$.

A parent is fecund only until period $K$, which imposes the additional constraint $b_{t}=0$ for $K<t \leq T$. This constraint is imposed to provide a motive for "hoarding" of children. If a child dies after period $K$, it cannot be replaced. The evolution of the number of children depends on the number of older children $n_{t}$, on whether there is a newborn $b_{t}$ and a young child $y_{t}$, and on the survival probabilities. Specifically, for a parent that has $n_{t}$ older children today, the probability of having $n_{t}+1$ tomorrow is zero when there is no young child and $s_{y}$ if a young child exists. Similarly, the probability of having a young child $y_{t}$ in the next period is $s_{i}$ if there is a newborn in this period, and zero otherwise. The probabilities over states are therefore defined recursively as:

$$
\begin{aligned}
P_{t+1}(n, y)= & P_{t}(n, 0)\left(1-y+(2 y-1) b_{t}(n, 0) s_{i}\right) \\
& +P_{t}(n, 1)\left(1-y+(2 y-1) b_{t}(n, 1) s_{i}\right)\left(1-s_{y}\right) \\
& +P_{t}(n-1,1)\left(1-y+(2 y-1) b_{t}(n-1,1) s_{i}\right) s_{y} .
\end{aligned}
$$

For example, consider the probability of having three old children and one young child in period six $(n=3, y=1)$. In this case, (1) reads:

$$
P_{6}(3,1)=P_{5}(3,0) b_{5}(3,0) s_{i}+P_{5}(3,1) b_{5}(3,1) s_{i}\left(1-s_{y}\right)+P_{5}(2,1) b_{5}(2,1) s_{i} s_{y} .
$$

The state $(n=3, y=1)$ can only be reached if in period five there are either three old children, or two old children and a young child. Therefore (2) sums over the respective probabilities $P_{5}(3,0), P_{5}(3,1)$, and $P_{5}(2,1)$ in period five. Also, there has to

labor and help in the household. The model could be extended to a richer cost profile. It is important, however, that children do not cause expenses forever, because then late-born children would be cheaper overall than older children. 
be a birth in period five, and the infant has to survive, since otherwise there would be no young child in period six. Therefore, each probability is multiplied by $b_{5}(n, y) s_{i}$. If the state in period five is $\{3,1\}$, there are three old children in period six only if the young child dies. Therefore, the respective probability is also multiplied by $1-s_{y}$. Finally, if there are only two old children in period five, the young child has to survive if there are to be three old children in period six. Hence, the last term is multiplied by $s_{y}$. The probability of having $n$ children survive into adulthood is:

$$
P(n)=P_{T}(n, 1)\left(1-s_{y}\right)+P_{T}(n, 0)+P_{T}(n-1,1) s_{y} .
$$

Birth decisions do not enter here, since there are no births in the final period of adulthood $T$. The decision problem in the sequential model is:

Model C: (Stochastic Barro-Becker with discrete and sequential fertility choice)

$$
\max _{\left\{b_{t}\right\}_{t=0}^{T}}\left\{\sum_{t=0}^{T} \sum_{h_{t} \in H_{t}} \gamma^{t} \frac{\left(w-p b_{t}\left(h_{t}\right)-q y_{t}\right)^{1-\sigma}}{1-\sigma} P_{t}\left(h_{t}\right)+\beta \sum_{n=0}^{N} n^{\epsilon} V P(n)\right\},
$$

where the probabilities over states $P_{t}\left(h_{t}\right)$ and surviving children $P(n)$ are functions of the birth decisions as defined in (1) and (3) above, and the initial probabilities are given by $P_{0}(0,0)=1$ and $P_{0}\left(h_{0} \neq\{0,0\}\right)=0$ (adults start without children).

Model C is related to the sequential fertility choice models developed by Sah (1991) and Wolpin (1997). In Sah's model, costs accrue only to surviving children, there is no limit to fecundity, and children survive for sure once they make it through the first period. Under the restrictions $p=0, s_{y}=1$, and $K=T$ our model is a special case of Sah's multi-period setup. Wolpin (1997) analyzes a three-period model (and employs a multi-period version for estimation) which allows for differential survival of infants and children and limits fecundity to the first two periods. Model $\mathrm{C}$ is a special case of Wolpin's model under the restrictions $T=2, K=1, \sigma=0$, and $q=0$.

A potential limitation of Model $\mathrm{C}$ is that we do not allow the household to borrow or lend in order to smooth income over time. This assumption may have an impact on the results if there is a lot of curvature in utility. However, the sensitivity analysis carried out in Section 5 will show that the main results are robust even when utility is close to linear, in which case there is little desire for consumption smoothing. 


\section{Analytical Findings}

In this section, I examine the effect of mortality decline on fertility in the three variants of the altruistic-parents model from an analytical perspective. As we will see, clearcut theoretical results on the mortality-fertility link are only available for a few special cases of the general model. Section 4 will complement the theoretical results derived here with quantitative findings from a calibrated model. All proofs are contained in the appendix.

Proposition 1 Let $b(s)$ denote the solution to Model $A$ as a function of $s . b(s)$ has the following properties:

- The number of surviving children $s b(s)$ is non-decreasing in s.

- If $p=0$ and $q>0$, fertility $b(s)$ is decreasing in $s$ and $s b(s)$ is constant.

- If $p>0$ and $q=0$, fertility $b(s)$ is increasing in s.

The intuition for these results is simple. Since parents care only about surviving children and there is no uncertainty, the survival probability $s$ affects choices only through the full cost of a surviving child $p / s+q$. Raising $s$ lowers this cost, and through the substitution effect therefore increases the number of surviving children.

In the special case where the cost $p$ for each birth is zero, the total cost of a surviving child is independent of $s$, and consequently parents choose the preferred number of surviving children irrespective of $s$. This implies that the total number of births declines in inverse proportion to $s$ as the survival probability increases.

When the cost component specific to surviving children $q$ is zero, the cost of a surviving child is inversely proportional to $s$. The reaction of the number of births $b(s)$ to changes in $s$ now depends on the price elasticity of the demand for (surviving) children. Given the assumptions $0<\epsilon<1$ and $0<\sigma<1$, this elasticity is bigger than one, so that the total number of births rises as the survival probability increases.

In summary, we see that in the deterministic model net fertility always rises as the survival probability increases. What happens to the total number of births depends on which cost component dominates. If a major fraction of the total cost of children 
accrues for every birth, fertility would tend to increase with the survival probability; the opposite holds if children are expensive only after surviving infancy.

I turn to the stochastic models next.

Proposition 2 Let $b(s)$ denote the solution to Model B as a function of $s$. If $p=0$, the optimal choice $b(s)$ is non-increasing in s.

Proposition 3 Let $b_{t}\left(h_{t}\right)\left(s_{i}\right)$ denote the solution to Model $C$ as function of the infant survival probability $s_{i}$ at a given state $h_{t}$. If $p=0$ and $s_{y}=1, b_{t}\left(h_{t}\right)\left(s_{i}\right)$ is non-increasing in $s_{i}$.

Thus in both stochastic models, we find that if there is no birth-specific cost, the optimal number of births declines as survival rates increase. The intuition from the deterministic model therefore carries over to the stochastic case. Only surviving children are costly, and surviving children is all the parents care about. Consequently, parents adjust their fertility to stay close to their preferred level of fertility. Notice, however, that even if $p=0$ in the stochastic model parents are no longer indifferent with regards to $s$. A higher survival probability reduces uncertainty about the number of surviving children, which, given risk aversion, increases expected utility. In the sequential model, in the case $p=0$ we can also show that age at first birth (weakly) increases with the survival probability. There are no clear-cut results, however, regarding net fertility. If utility is highly concave in $n$, parents want to avoid a low number of surviving children. If mortality is high, this can give rise to a precautionary demand for children or "hoarding," which declines as mortality (and therefore uncertainty) decreases. However, the opposite effect is also possible, since utility is concave in consumption as well. If parents are very risk averse in terms of consumption, they might want to avoid the risk of having too many surviving children (and thereby high expenditures on children), which would lower the number of births when mortality is high. While these effects apply in principle to both Model B and Model C, the model with sequential fertility choice is in some sense in between the deterministic and the stochastic model. Since choices are spread out over time, in this case parents have the possibility of replacing children that die early in the life cycle, leading to less uncertainty over the realized number of children than in Problem B, where all children are born simultaneously. 
For similar reasons, no general results are available for the case $p>0$, even if $q=0$. In the deterministic model, in this case total fertility $b(s)$ increases in $s$. In the stochastic model, the opposite may be true if the precautionary motive for having children is important. Consider the case of a parent whose primary concern, due to high risk aversion, is to avoid being left without any surviving children. Fertility will be highest when mortality is high as well, since the parent has to rely on a "law of large numbers." The number of births would decline if an increased survival probability lowered uncertainty about the number of surviving children.

The theoretical analysis identifies two important factors which influence the child mortality-fertility nexus: the relative cost of dying and surviving children, and the degree of risk aversion regarding the number of surviving children. Since both factors depend nontrivially on model parameters, the question whether reductions in child mortality increase or decrease net fertility is ultimately quantitative in nature.

\section{Quantitative Findings}

The analytical results show that all three models are consistent with declining total fertility rates (i.e., number of births) in response to falling mortality. However, we are left without a clear-cut prediction for the relationship of child mortality to net fertility (i.e., number of survivors). Only the deterministic model unambiguously predicts that the number of surviving children will rise as mortality falls. In the more elaborate stochastic models, the relationship could go either way. Therefore, I assess the quantitative predictions of the models with a calibration exercise. Each model is parameterized to reproduce mortality and fertility rates in England in 1861, when infant and child mortality was still high. I then increase the survival parameters to correspond to mortality rates in 1951 (by which time most of the fall in infant and child mortality had been completed) and compare the predictions of each model for the impact on fertility rates.

The models are parameterized as follows. In the sequential model, we set $T=14$ and $K=12$, so that the maximum number of births is 13 . Income $w$ is a scale parameter

and is set to 1 per period in the sequential model and 14 in the other models. The parameter $p$ corresponds to the cost of a child until its first birthday, while the pa- 
rameter $q$ accounts for the remaining cost. In terms of goods, it is natural to assume that the yearly cost increases until the child is able to work and partly pay for itself. The time cost, on the other hand, decreases over time. In addition, the cost per birth should account for the cost of pregnancy and the risk of the mother's death during childbirth. Since time and goods cost move in opposite directions, I assume as the baseline case that overall cost is proportional to age, and that children are no longer a net burden once they are six years old. I therefore set $q / p=5$. The overall level of the cost parameters is set such that in the sequential model, a household with both an infant and a young child spends half of its income on the children. This gives $p=1 / 12$ and $q=5 / 12$. The curvature parameters in the utility function are set to $\sigma=\epsilon=1 / 2$, and the discount factor in the sequential model is $\gamma=0.95$. The children's utility level $V$ is equated to the parent's utility in each case (i.e., the steady-state utility that would obtain with constant income and mortality rates).

The survival parameters are chosen to correspond to the situation in England in 1861. According to Preston, Keyfitz, and Schoen (1972) the infant mortality rate (death rate until first birth rate) was 16 percent, while the child mortality rate (death rate between first and fifth birthday) was 13 percent. Accordingly, I set $s_{i}=0.84$ and $s_{y}=0.87$ in the sequential model, and $s=s_{i} s_{y}=0.73$ in the other models. Finally, the altruism factor $\beta$ is set in each model to match the total fertility rate, which was 4.9 in 1861 (Chesnais 1992). Since fertility choice is discrete in Models B and C, I chose a total fertility rate of 5.0 as the target.

Each model is thus calibrated to reproduce the relationship of fertility and infant and child mortality in 1861. I now examine how fertility adjusts when mortality rates fall to the level observed in 1951, which is 3 percent for infant mortality and 0.5 percent for child mortality. The results for fertility can be compared to the observed total fertility rate of 2.1 in 1951.

In Model A (Barro-Becker with continuous fertility choice), the total fertility rate falls from 5.0 (the calibrated target) to 4.2 when mortality rates are lowered to the 1951 level. The expected number of surviving children increases from 3.7 to 4.0. Thus, there is a small decline in total fertility, but (as was to be expected given Proposition 1) an increase in the net fertility rate.

Perhaps surprisingly, the results generated by Model B (stochastic Barro-Becker with discrete fertility choice) are very similar to Model A. In the stochastic model, total 
fertility falls from 5.0 to 4.0 , and net fertility increases from 3.7 to 3.9. Fertility falls by more than in the deterministic model, but the difference is small.

In Model C (sequential fertility choice), the total fertility rate is not an integer since it depends on the random individual mortality realizations. Therefore, $\beta$ was chosen to move the total fertility rate to 5.2 , which is the closest possible match to the target of 5.0. When mortality is lowered to 1951 levels, fertility falls only to 5.0, while net fertility increases substantially from 3.8 to 4.8 . These results are partly due to the fact that the sequential model distinguishes infant and child mortality, while the other models do not. The sequential model probably overstates the cost of child mortality, since we assume that the entire cost $q$ has to be paid if a child dies, even though most of child mortality is concentrated near the beginning of the interval from one to five years of age. The models line up more closely if we set $s_{y}=1$ and assign the entire fall in mortality to infant mortality $s_{i}$ (as we do implicitly in the other two models). In this case, total fertility falls from 5.1 to 4.0 , while net fertility increases from 3.7 to 3.9. This is identical to the results with Model B.

Figures 1 to 3 show that the predictions of the models are similar for the entire range of possible infant mortality rates (the solid line is the total fertility rate, and the dotted line is the net fertility rate; for Figure 3, child mortality was set to $s_{y}=1$ ). The sequential model yields additional predictions for the age at first birth, which increases with the survival probability once $s_{i}$ is at least 10 percent (Figure 4 ). This increase not only reflects the corresponding decline in total fertility, but also narrower spacing of births. When mortality is high, parents start having children early so that there is time to make up for children who die. This replacement motive is less important when survival rates are high.

In terms of guiding the applied researcher, our results show that once the differential cost of dying and surviving children is accounted for, the deterministic Barro-Becker model leads to virtually the same conclusions as the stochastic model with sequential fertility choice. Thus, unless questions concerning birth order and timing are of particular interest (as in Caucutt, Guner, and Knowles 2002), the basic model can be used as a stand-in for the more elaborate setup.

In all computations, the children's utility $V$ was held constant. However, results are virtually unchanged if $V$ is adjusted to reflect the steady-state utility at each value of $s$. This utility increases in $s$ since the cost of surviving children falls as $s$ increases, 
while uncertainty is reduced. If the effect of $s$ on utility were taken into account, we would observe an additional upward effect on (both net and gross) fertility rates as $s$ increases. Quantitatively, this effect is small. We also disregard the increase in income per capita over the period, since with the chosen functional forms fertility is independent of the level of income, as long as the cost of children is proportional to income. This is approximately true if a major part of the cost of children is either a direct time cost or is tied to the level of wages. If there is a sizable goods component in the cost of children, children become relatively more affordable as wages rise, which once again would exert an upward effect on fertility. Thus, accounting for the dependency of $V$ on $s$ or the effect of rising wages can only strengthen our basic conclusions.

In summary, each model predicts that total fertility falls with infant mortality, but none of the models predicts a fall in net fertility rates. Relative to the data, the models suggest that only a small proportion of observed fertility decline, and none of the net fertility decline, is accounted for by declining infant mortality.

\section{Sensitivity of the Results}

The quantitative results in the preceding section were obtained for specific, calibrated parameter values. The question arises whether the results are sensitive to the choice of parameters. In other words, are there reasonable parameter values for which any of the models predict a substantial decline in net fertility as infant mortality declines? We know from Proposition 1 that this can never be the case in Model A. In the other models, however, a "precautionary" demand for children can arise if parents' utility is highly concave in the number of children, but close to linear in consumption. The curvature of utility is governed by the parameters $\sigma$ and $\epsilon$. To examine the sensitivity of the results, the computations were repeated with $\sigma$ and $\epsilon$ varying independently from 0.01 to 0.99 (on a grid with four values per parameter, or 16 possible combinations). In each case, the discount factor $\beta$ was adjusted to keep fertility at 5.0 given observed mortality rates in 1861 . As was to be expected, we find that in Model B a precautionary demand for children arises if risk aversion with respect to children is high, while risk aversion with respect to consumption is low. In Model C with sequential fertility choice, however, the relationship between mortality and fertility is surprisingly robust with respect to the choice of utility parameters. Specifically, we 
did not find a single case where in an increase in the survival probability results in substantial net fertility decline.

To illustrate this point, let us consider the extreme case of $\sigma=\epsilon=0.01$. Here utility from consumption is close to linear, while risk aversion with regards to the number of surviving children is high. The discount factor $\beta$ is adjusted to keep fertility at 5.0 given 1861 mortality rates. If we now lower mortality rates to the level of 1951, in Model B total fertility falls from 5.0 to 2.0, and net fertility from 3.7 to 1.9. This effect disappears entirely, however, when we move (with the same parameters) to the more realistic sequential model, where parents can replace children who die early. Here, despite the high risk-aversion with regards to the number of children, total fertility drops only to 4.0 , and net fertility rises to 3.9 , just as with the benchmark parameters. Figures 5 and 6 show fertility rates over the entire range of mortality rates in the two models. Thus, in the sequential setup the conclusion that mortality decline raises net fertility is robust to different preference specifications, even if we deliberately emphasize the precautionary motive for hoarding children.

Another parameter which could potentially have an important impact on the results is the fecundity limit $K$ in the sequential model. If less time is available to replace children once mortality is experienced, the hoarding motive might be expected to become more important. In the computations, however, this did not turn out to be the case. As long as $K>7$, the results were virtually unaffected by the choice of $K$. For $K \leq 6$, the fertile period is too short for fertility rates to increase significantly as the survival probability declines, which limits the possibility of hoarding. Once again, the basic conclusion remains that net fertility does not fall as mortality declines, regardless of the choice of $K$.

Finally, the total cost of children and its distribution between a cost per birth and per surviving child might influence the results. We know from the theoretical results that the hoarding motive is more likely to be important if the cost per birth is low. However, even in the extreme case of $p=0$ (cost per birth is zero) the model predictions change very little from what is displayed in Figures 1 to 6 . In the sequential model with $p=0$ and the utility parameters $\sigma=\epsilon=0.01$ (the case most favorable for the hoarding motive) net fertility increases by 0.2 if mortality is lowered from 1861 to 1951 levels, just as in the baseline case. Likewise, varying the overall cost of children (relative to income) has hardly any effect, as long as we adjust the discount factor to 
control for initial fertility.

The overall results of the sensitivity analysis suggest that at least in the sequential fertility choice model (which is the most realistic case) the curvature of utility has little effect on the child mortality-fertility relationship. The possibility of replacing a child after a death occurs implies that the hoarding motive plays only a minor role. Instead, child mortality affects fertility chiefly through the total cost of surviving children, which is exactly the channel emphasized by the deterministic Barro-Becker model. This also explains why the predictions of the deterministic and the sequential model are remarkably similar in a variety of circumstances.

\section{Theoretical Results versus Empirical Findings}

The analysis in the preceding sections led to a clear conclusion. Over the empirically relevant range of mortality rates, a reduction in child and infant mortality results in a decline in total fertility rates, but not in net fertility rates. In this section, I contrast these theoretical predictions to empirical evidence on the child mortality-fertility link. While there is inevitable variation in the empirical results, the preponderance of the available evidence supports the predictions of the theoretical model.

A significant part of the empirical literature focuses on the experience of Western European countries during the demographic transition. To provide a first impression of the data, Figures 9 to 13 plot the evolution of birth rates and infant mortality rates from 1835 to 1940 in the United Kingdom, France, Germany, Sweden, as well as the United States. ${ }^{6}$ In each case, fertility and infant mortality decline substantially over the period. However, there is no general pattern regarding the relative timing of fertility and mortality decline. In the United Kingdom, substantial fertility decline started before 1880. Infant mortality was still high at the time, and actually rose during the first two decades of substantial fertility decline. Infant mortality started declining rapidly only after 1900 . The British experience therefore suggests that mortality decline follows fertility decline. France had a similar experience. Fertility was already in decline in 1830, and the downward trend continued throughout the nineteenth

\footnotetext{
${ }^{6}$ Birth rates were used instead of total fertility rates since they are more widely available, especially at the beginning of the period.
} 
century. Infant mortality, in contrast, stayed high until close to 1900. The experience of the U.K. and France therefore appears to contradict the hypothesis that infant mortality decline was a main causing factor of fertility decline during the transition.

The situation is different, however, in Germany and Sweden. In both cases, sizable reductions in infant mortality took place before the main phase of fertility decline. Subsequently, fertility and infant mortality fell in tandem as the demographic transition progressed. The U.S. data is less reliable and partially based on estimates, because comprehensive registration of deaths and births did not occur before the twentieth century. Nevertheless, the pattern bears some similarity to the French example. Fertility fell from the beginning of the nineteenth century, whereas infant mortality was substantially reduced only after 1880 .

Our cursory examination of the evidence does not reveal a clear one-way link from mortality decline to fertility decline, or, for that matter, the other way around. A more comprehensive review of the European evidence from this period is provided by van de Walle (1986). Using province level data from a variety of countries, van de Walle computes the correlation of the change in fertility with the change in infant mortality during the period 1870 to 1930 . If infant mortality declines were a major cause of fertility decline, we would expect the correlation to be positive. However, the results are mixed at best. In most cases, the estimated correlation is not significantly different from zero; the few significantly positive estimates are offset by others which are significantly negative. Van de Walle also considers the relative timing of fertility and mortality decline in different provinces of a country. The start of the fertility or mortality transition is defined as the first time when the respective index is at least 10 percent below its pre-transition level. Again, the evidence is mixed. In Switzerland, in the vast majority of districts infant mortality decline precedes fertility decline. In Germany, there is an about equal number of districts with fertility or mortality falling first. In the case of Belgium and England, finally, fertility generally declines before infant mortality does.

The German case is analyzed in more detail by Galloway, Lee, and Hammel (1998), who examine family-level data from Prussia in the period 1875 to 1910. Unlike most empirical studies, Galloway, Lee, and Hammel employ two-stage least squares estimation to deal with potential two-way causality between child mortality and fertility. In regressions that exploit the cross-sectional variation across cities and districts in 
their data set, little evidence for a significant relationship of child mortality and fertility is found. On the other hand, when a fixed effect for each district is introduced (so that only the time-series variation in each district is exploited) a strong positive relationship between child mortality and fertility arises. In rural districts, fertility changes with mortality about one-to-one, while the reaction in cities is even larger. The estimates therefore would imply that, at least in the cities, mortality decline led to a reduction in net fertility rates. It is not clear, however, how reliable these estimates are. Both fertility and mortality have a strong downward time trend during the period considered, which could lead to biased and imprecise estimates. The authors themselves state that their fixed-effect estimates probably overstate the true effect of child mortality on fertility.

A similar study using more recent data is carried out by Rosero-Bixby (1998), who analyzes county-level data from Costa Rica during the fertility transition. Apart from demographic data, the data set includes a variety of county characteristics which could also affect fertility. Once these other county-specific effects are controlled for, no evidence in favor of a causal link from child mortality decline to fertility decline during the transition is found.

The causes of fertility decline during the demographic transition in Sweden are examined by Eckstein, Mira, and Wolpin (1999). Their study is particularly relevant from the perspective of this paper, since long-run empirical data is analyzed using an estimated dynamic model of fertility choice. The model allows for multiple life-cycle periods, multiple births, and includes goods and time costs for children. As in the models discussed here, there is a cost differential between surviving and dying children: the goods accrues for all children, whereas the time cost only applies if a child survives to the next period. Compared to the sequential model presented in Section 2, the most important difference is that mortality is deterministic. A given percentage of children survives until the next period, so there is no uncertainty about the number of surviving children.

The model parameters are chosen to fit model predictions to Swedish data on child and adult mortality rates, fertility rates, and real wages from 1736 and 1946. Using the estimated model, Eckstein, Mira, and Wolpin perform a series of counterfactual experiments to determine the contributions of different potential explanations to overall fertility decline. In order to isolate the role of infant and child mortality, 
the authors feed the historical pattern of declining infant and child mortality into the model, while holding wages and adult mortality constant. The resulting predictions of the model are consistent with our findings: the total fertility rate falls in response to declining mortality, but the net fertility rate increases. A similar experiment using adult mortality rates reveals only a weak relationship between adult mortality and fertility. When the effect of rising wages is isolated, both total and net fertility rates decline, if only by a relatively small amount.

A particularly interesting result is that the combined effect of raising wages and lowering infant and child mortality at the same time much exceeds the sum of the two effects in isolation. To see the intuition for this result, recall that rising wages lower fertility through a substitution effect, since the time cost of raising children increases. When infant mortality falls, this time cost makes up a larger fraction of the total cost of a child, since the additional goods cost has to be paid regardless whether a child survives. Therefore, when mortality is low, rising wages have a relatively larger effect on the total cost of a child, which amplifies the impact on fertility rates. Thus, while child mortality decline per se does not decrease net fertility, it still contributes indirectly through the interaction with rising wages. In Section 7 we will explore whether a similar effect can arise in our model.

In addition to evidence related to fertility decline during the demographic transition, there is also a sizable empirical literature which uses cross-sectional data to assess the link of child mortality and fertility. In a seminal study, Ben-Porath (1976) analyzes a retrospective survey of the birth history of married women in Israel. Based on data for the period 1960-1963, Ben-Porath finds strong evidence for the replacement effect. That is, experiencing the death of a child increases the number of births and reduces the intervals between births. The degree of replacement varies with the origin of the mother and the birth order. For example, among mothers of Asian or African descent, close to 80 percent of child deaths are replaced at birth order 2 or 3 . The replacement effect declines at higher birth orders, and is generally weaker for mothers of Israeli, European, or American descent. Since the replacement effect is always below 100 percent, in all cases a decline in mortality would imply an increase in net fertility.

Knodel (1978) emphasizes that in addition to deliberate attempts to control fertility, child mortality decline can also affect fertility when any deliberate fertility control is absent. It has long been recognized that breastfeeding tends to delay further preg- 
nancy. The death of an infant therefore raises the probability of further births through the premature interruption of breastfeeding. Knodel compares the effect of infant mortality on subsequent births in German and French regions in different time periods between 1640 to 1900, mostly from the period before the onset of substantial fertility decline. Confirming the physiological link between child mortality and fertility, Knodel finds is that the effect of a child's death on fertility is particularly small in areas where breastfeeding is known to be uncommon.

Haines (1998) provides a study using data from the 1900 and 1910 U.S. censuses which allows a separation of replacement and hoarding effects. He finds that at the turn of the century, between 10 to 30 percent of child deaths were replaced through higher subsequent fertility. The hoarding effect is estimated to amount to 30 to 50 percent of a child per death, resulting in a total effect in the neighborhood of 60 to 80 percent. Once again, these numbers imply that fertility decline would raise total fertility, but lower net fertility.

A number of studies of fertility behavior in developing countries find that factors other than replacement and hoarding behavior have to be taken into account to interpret the evidence. Using data from Colombia, Costa Rica, Mexico, and Peru for the years 1969-1970, Rutstein and Medica (1978) come to the surprising finding that in a number of regions rises in infant mortality lead to a decrease in subsequent fertility. The authors conjecture that the health problem leading to the death of the child (usually an infectious disease) might also affect the mother, thereby shortening fecundity and subsequent fertility. Also, in a number of regions fertility is close to the natural limit, leaving little room for a replacement effect. In an analysis of data from Taiwan, Heer and $\mathrm{Wu}$ (1978) put the spotlight on a yet another variable: the sex of the child. While the death of a child generally increases subsequent fertility, the increase is significantly lower if there are already three surviving sons as opposed to three surviving daughters. Defo (1998) finds that in Cameroon, birth order matters. The death of a first child has a much larger impact on completed fertility than the death of a child higher in the birth order. Gender also matters, with surviving boys lowering the probability of further pregnancies. Defo attributes this result to the special role played by first-borns in Cameroonian culture.

To summarize, the majority of the cross-sectional studies find strong evidence in favor of a replacement effect: fertility increases after the death of a child is experienced. 
This increase is generally less than one-to-one, however, so that lost children are not replaced completely. The cross-section evidence therefore supports the main conclusions of our model, namely, that total fertility falls and net fertility increases as child mortality rates decline. In addition, the empirical studies show that a number of other factors not captured in our theoretical models also matter for the mortality-fertility relationship. Examples include the physiological effect which arises from interrupted breastfeeding, as well as the differential response to a child's death depending on the sex of the existing children.

\section{An Extension with Endogenous Education Decisions}

The main result of this study so far is a negative one, namely, falling child mortality is unlikely to have caused the large decline in net fertility observed during the demographic transition. However, our theoretical framework is consistent with other explanations of the same facts. In particular, a number of authors ${ }^{7}$ who use the BarroBecker model interpret fertility decline as a quantity-quality substitution: parents have fewer children in order to invest more in each child. In this section, I extend Model $\mathrm{A}^{8}$ by allowing the parents to invest into the education of their children. This education choice introduces a quantity-quality tradeoff which can serve as an explanation for fertility decline. I then explore whether infant and child mortality interacts with the quantity-quality tradeoff. Eckstein, Mira, and Wolpin (1999) point out that in their model such an interaction is important: mortality reductions per se increase net fertility, but in combination with rising real wages they can amplify the negative total effect on fertility. As we will see, our model does not lead to the same conclusion. To the contrary, allowing for endogenous education choice strengthens the positive effect of mortality decline on net fertility.

In the extended model, a parent can invest fraction $e$ of its time in the education of its

\footnotetext{
${ }^{7}$ Examples include Becker, Murphy, and Tamura (1990), de la Croix and Doepke (2003), Doepke (2001), and Fernández-Villaverde (2001).

${ }^{8}$ For simplicity, the exposition is limited to the deterministic model. We already established that the deterministic and the sequential model have very similar implications for the link between child mortality and fertility. The extension considers investments which are best thought of as taking place after mortality or survival have been realized. That is, we are considering a stage where the remaining choice problem of optimally investing in children is identical in all three versions.
} 
surviving children. We assume that the cost only accrues to surviving children, since by definition child mortality affects children under the age of six, the age at which (formal) education usually begins. ${ }^{9}$ The remaining fixed costs $p$ (per birth) and $q$ (per surviving child) are expressed as fractions of the parent's time as well. The distinction between time and goods costs was immaterial for the analysis so far, but it will play an important role here. Assuming that all costs are in terms of time implies that the total cost of children is proportional to income. ${ }^{10}$

To introduce a motive for education, a person's income now has two components. There is a basic wage $\underline{w}$ for "raw labor" that a person gets regardless of their education, and an additional wage $w$ per unit of human capital $h$. The education provided by parents is converted into children's human capital $h^{\prime}$ by a concave, increasing function $h(e)$ which satisfies $h(0)=0$. Under the assumption that wages and the survival probability $s$ are constant, the parent's utility can be described by a value function $V(h)$ which satisfies the Bellman equation:

$$
V(h)=\max _{n, b, e}\left\{\frac{c^{1-\sigma}}{1-\sigma}+\beta n^{\epsilon} V\left(h^{\prime}\right)\right\}
$$

subject to:

$$
\begin{aligned}
c & =(\underline{\mathrm{w}}+w h)(1-p b-(q+e) n), \\
n & =s b, \\
h^{\prime} & =h(e) .
\end{aligned}
$$

In the endogenous education framework, two potential determinants of fertility decline can be distinguished: changes in the survival probability $s$, and changes in the importance of human capital, as measured by the wage $w$. To assess the relative importance of these factors, the model has to be solved numerically. The value function $V(h)$ and the optimal policy functions $n(h), b(h)$, and $e(h)$ can be computed through value function iteration. The predictions of the model for a given set of parameters

\footnotetext{
${ }^{9}$ Our results would be modified if education started before child mortality is realized, since then mortality reductions would lower the effective cost of education (see Kalemli-Ozcan 2002 and Soares 2003). However, since most education occurs after age six, and most of child mortality is concentrated at the youngest ages, quantitatively this effect is bound to be small.

${ }^{10}$ If we assumed that some of the costs were in terms of goods, the total cost of children would decline relative to income as wages grow, leading to higher fertility than in the case of time costs.
} 
are evaluated at the steady state level of human capital $\bar{h}$, that is, the level of human capital that satisfies $\bar{h}=h(e(\bar{h}))$.

The calibration of the endogenous education model follows the same strategy used for the other models. Hence, the model parameters are chosen to match observed mortality and fertility rates in 1861. As far as possible, the same parameters were used as in the baseline calibration of Model A. We therefore set $\sigma=\epsilon=0.5, \underline{w}=w=$ $14 \times \frac{2}{3}=9.33, p=1 / 168$, and $q=5 / 168 .{ }^{11}$ The functional form used for $h(e)$ is:

$$
h(e)=A \sqrt{e},
$$

where $A$ is chosen such that $h=1 / 2$ obtains in the initial steady state. Notice that given these parameters, total income $\underline{\mathrm{w}}+w h$ matches its value of 14 in the original calibration. Finally, $\beta$ is chosen to match the observed total fertility rate of 5.0 in 1861, given the actual infant and child mortality rates in that year.

Figure 7 shows the relationship between child mortality and fertility in the model given the 1861 calibration. The value function was computed separately for each value of the survival probability, and steady state fertility rates are displayed for each s. As in Model A, we observe that the relationship between $s$ and total fertility is hump-shaped, while net fertility is strictly increasing in $s$. The key difference to Figure 1 (which displays the same relationship in Model A without the education choice) is that the maximum fertility level is significantly lower with endogenous education choice. In Figure 1, the total fertility rate peaks at 7.8 when the mortality rate is $s=0.2$, while in Figure 7 the maximum is 6.2 at $s=0.35$.

Let us now consider the observed fertility and mortality rates in 1951. By increasing the human-capital component $w$ of the total wage (or, equivalently, the productivity $A$ of the education technology $h(e))$, we can induce a quantity-quality substitution which lowers the total fertility rate to the observed level of 2.1 in 1951, given the survival probability of $s=0.965$ in that year. ${ }^{12}$ Figure 8 shows the entire relationship between mortality and fertility for this calibration. As in all models considered so far, net fertility is strictly increasing in $s$, and total fertility is hump-shaped with a

\footnotetext{
${ }^{11}$ Notice that the original costs of $p=1 / 12$ and $q=5 / 12$ are divided by the total wage $\underline{w}+w h=14$, since they are now interpreted as a time cost.

${ }^{12}$ To achieve this, $w$ has to increase by a factor of 3.05, which is smaller than the observed increase in real wages over the same period.
} 
maximum fertility rate of 2.8 .

Figure 8 also helps to answer the question whether mortality decline contributed to fertility decline through an interaction with the quantity-quality tradeoff. What would have happened if wages had increased as assumed in the calibration, but mortality rates had stayed at their 1861 level? The answer can be read off Figure 8 at the 1861 mortality rate of $s=0.73$ : The total fertility rate would have been 2.4 , and the net fertility rate 1.8. This compares to total and net fertility rates of 2.1 and 2.0 under the actual mortality rate of $s=0.965$. Thus, had mortality remained at its 1861 level, the decline in the net fertility rate would have been even larger than it was in reality. Mortality decline therefore did not contribute to declining net fertility, even through the indirect route.

It is instructive to compare this result to Eckstein, Mira, and Wolpin (1999), who fit a theoretical model of fertility choice to Swedish data, and carry out a series of counterfactual experiments to assess the contributions of child mortality decline and wage increases to fertility decline. Concentrating on the period 1856 to 1946, they find that mortality decline alone with wages held constant at their initial level would have lowered the total fertility rate by 0.62 . Feeding only the observed wage increase into the model while holding mortality constant leads to decrease in total fertility of 0.85 . The sum of the two isolated effects is therefore a decline of 1.47. If both mortality and wages change at the time, however, the combined effect is a decline of 1.81, which much exceeds the sum of the individual effects. Let us now consider the same calculations in our model with endogenous education choice. Starting from the 1861 calibration, raising the survival probability from 0.73 to 0.965 while holding wages constant lowers the total fertility rate by 0.8 . Increasing wages by a factor of 3.05 while holding mortality constant lowers total fertility by 2.6. The sum of the two isolated effects is therefore a decline of 3.4 in total fertility, which compares to a combined effect of minus 2.9 if both changes take place at the same time. Thus, in our model the combined effect is smaller than the sum of the two isolated effects.

Thus, unlike in Eckstein, Mira, and Wolpin (1999), child mortality decline does not amplify the negative effect of rising wages on fertility. The results differ because wages affect fertility through a different channel in the two models. The model of Eckstein, Mira, and Wolpin does not allow for investments in children. The level of wages affects fertility through an income and a substitution effect. Fertility falls as 
wages rise because the substitution effect is stronger than the income effect. If child mortality is low, the time cost (which depends on the wage) makes up a larger part of the total cost of children. This amplifies the substitution effect and leads to a larger fertility decline in response to wages.

In the Barro-Becker model, a change in the level of wages per se (holding education constant) does not change fertility: the substitution effect and the income effect exactly offset each other ${ }^{13}$. However, the level of wages can still affect fertility indirectly, through the optimal choice of child quality versus child quantity. As wages rise, child quality becomes more attractive, which raises education and lowers fertility. Notice, however, that a decline in child mortality does nothing to amplify this effect. Quite to the contrary, a decline in child mortality lowers the cost of every child, which tends to favor quantity over quality. Indeed, in the computations underlying Figures 7 and 8 the optimal education choice $e$ declines as the survival probability $s$ rises.

The Barro-Becker model with endogenous education choice does not confirm the finding of Eckstein, Mira, and Wolpin (1999) that declining child mortality amplifies the negative effect of wages on fertility. While such an effect is possible if preferences are non-homothetic (as in Eckstein, Mira, and Wolpin), it cannot arise through an interaction of child mortality with a quantity-quality tradeoff in the decisions on children. To the extent that increased investment in the quality of children is responsible for fertility decline, child mortality is not an important contributor even on the indirect route.

\section{Conclusions}

All of the models discussed in this paper lead to the same conclusion: declines in child mortality lower total fertility rates, but do not cause decreases in net fertility. The findings are robust with respect to the inclusion of stochastic mortality, sequential fertility choice, and endogenous education decisions. The empirical evidence on the mortality-fertility relationship is also consistent with our findings.

\footnotetext{
${ }^{13}$ This result is based on two assumptions: homothetic preferences, and proportionality of wages and the cost of children
} 
The basic intuition for the results is simple. If what parents care about is surviving children, a reduction in mortality implies that the cost of having a surviving child declines. Assuming that children are a normal good, we would expect a rise in the demand for children, and therefore an increase in the net fertility. What happens to overall fertility then depends on the price elasticity of demand for children. If demand is very elastic, the total fertility rate could increase as mortality declines. However, if mortality is relatively low already, a further decline in mortality induces only a small change in the overall cost of having a child. We would therefore expect that at low mortality rates a further reduction in mortality leads to a less-than-proportional increase in net fertility, and therefore a decrease in total fertility. The results in Figures 1 to 8 bear this out: in each model, the total fertility rate increases in the survival probability $s$ for low $s$ (where an increase in $s$ has a large effect on the total cost of a surviving child), but the relationship turns around for high $s$.

Our quantitative analysis shows that these findings stay intact even if we account for stochastic mortality and sequential fertility choice. Contrary to our results, a number of existing studies argue that with stochastic mortality a large precautionary demand for children arises, which would lead to a negative effect of mortality decline on net fertility. There are two reasons why we come to different conclusions than the existing literature. First, the risk-aversion argument cuts both ways. Parents who decide to have a very large number of children are hedging against many of them dying, but at the same time they expose themselves to the risk of many of them surviving, meaning that they would have to support a large group of children and would have to lower their own consumption. Hence, risk aversion with respect to the parent's own consumption tends to work against a precautionary demand for children. Second, and perhaps more importantly, the sequential nature of fertility choice also tends to lower the precautionary demand for children. Since most of mortality is concentrated very early in life, parents can adopt a "wait-and-see" stance, produce their desired number of children, and simply replace those that happen to die early in life. This replacement strategy is not perfect, because fecundity is limited and it might turn out to be impossible to get another child. Nevertheless, the possibility of replacement greatly mitigates the precautionary demand for children, to the extent that in the calibrated model it is nearly impossible to generate such a demand.

Even though we do not assign an important to role to child mortality decline per se, 
our results do not rule out that mortality decline might interact with other explanations for fertility decline. For example, in the model by Eckstein, Mira, and Wolpin (1999), child mortality decline amplifies the effect of rising wages on fertility. We find that such an amplification effect does not occur, however, if a quantity-quality tradeoff is the driving force behind fertility decline. In the model presented in Section 7, rising wages increase the role of human capital, which induces parents to lower fertility and invest more in the education of their children. Mortality decline does not strengthen this effect. To the contrary, since mortality decline lowers the cost of every child equally, it favors quantity over quality and slows fertility decline. 


\section{References}

Barro, Robert and Gary S. Becker. 1989. "Fertility Choice in a Model of Economic Growth." Econometrica 57 (2): 481-501.

Becker, Gary S., Kevin M. Murphy, and Robert Tamura. 1990. “Human Capital, Fertility, and Economic Growth." Journal of Political Economy 98:12-37.

Ben-Porath, Yoram. 1976. "Fertility Response to Child Mortality: Micro Data from Israel." Journal of Political Economy 84 (4): S163-S178.

Boldrin, Michele and Larry E. Jones. 2002. "Mortality, Fertility, and Saving in a Malthusian Economy." Review of Economic Dynamics 5 (4): 775-814.

Boucekkine, Raouf, David de la Croix, and Omar Licandro. 2002. "Vintage Human Capital, Demographic Trends, and Endogenous Growth." Journal of Economic Theory 104 (2): 340-75.

Caucutt, Elizabeth M., Nezih Guner, and John Knowles. 2002. "Why Do Women Wait? Matching, Wage Inequality, and the Incentives for Fertility Delay." Review of Economic Dynamics 5 (4): 815-855.

Chesnais, Jean Claude. 1992. The Demographic Transition. Oxford: Oxford University Press.

de la Croix, David and Matthias Doepke. 2003. "Inequality and Growth: Why Differential Fertility Matters." American Economic Review 93 (4): 1091-113.

Defo, Barthélémy Kuate. 1998. "Fertility Response to Infant and Child Mortality in Africa with Special Reference to Cameroon." Chapter 8 of From Death to Birth: Mortality Decline and Reproductive Change, edited by Mark R. Montgomery and Barney Cohen. Washington, D.C.: National Academy Press.

Doepke, Matthias. 2001. "Accounting for Fertility Decline During the Transition to Growth." UCLA Department of Economics Working Paper No. 804.

Eckstein, Zvi, Pedro Mira, and Kenneth I. Wolpin. 1999. "A Quantitative Analysis of Swedish Fertility Dynamics: 1751-1990." Review of Economic Dynamics 2:137-165.

Fernández-Villaverde, Jesús. 2001. “Was Malthus Right? Economic Growth and Population Dynamics." Unpublished Manuscript, University of Pennsylvania.

Galloway, Patrick R., Ronald D. Lee, and Eugene A. Hammel. 1998. “Infant Mortality and the Fertility Transition: Macro Evidence from Europe and New Findings from Prussia." Chapter 6 of From Death to Birth: Mortality Decline and Reproductive Change, edited by Mark R. Montgomery and Barney Cohen. Washington, D.C.: National Academy Press.

Galor, Oded and David N. Weil. 2000. "Population, Technology, and Growth: From Malthusian Stagnation to the Demographic Transition and Beyond." American Economic Review 90 (4): 806-28. 
Greenwood, Jeremy and Ananth Seshadri. 2002. “The U.S. Demographic Transition." American Economic Review Papers and Proceedings 92 (2): 153-159.

Haines, Michael R. 1998. "The Relationship between Infant and Child Mortality and Fertility: Some Historical and Contemporary Evidence for the United States." Chapter 7 of From Death to Birth: Mortality Decline and Reproductive Change, edited by Mark R. Montgomery and Barney Cohen. Washington, D.C.: National Academy Press.

Heer, David M. and Hsin-Ying Wu. 1978. "Effects in Rural Taiwan and Urban Morocco: Combining Individual and Aggregate Data." Chapter 7 of The Effects of Infant and Child Mortality on Fertility, edited by Samuel H. Preston. New York: Academic Press.

Kalemli-Ozcan, Sebnem. 2002. "Does the Mortality Decline Promote Economic Growth?" Journal of Economic Growth 7 (4): 411-39.

- 2003. "A Stochastic Model of Mortality, Fertility, and Human Capital Investment." Journal of Development Economics 70 (1): 103-18.

Knodel, John. 1978. "European Populations in the Past: Family-Level Relations." Chapter 2 of The Effects of Infant and Child Mortality on Fertility, edited by Samuel H. Preston. New York: Academic Press.

Preston, Samuel H., Nathan Keyfitz, and Robert Schoen. 1972. Causes of Death: Life Tables for National Populations. New York: Seminar Press.

Rosero-Bixby, Luis. 1998. "Child Mortality and the Fertility Transition: Aggregated and Multilevel Evidence from Costa Rica." Chapter 11 of From Death to Birth: Mortality Decline and Reproductive Change, edited by Mark R. Montgomery and Barney Cohen. Washington, D.C.: National Academy Press.

Rutstein, Shea and Vilma Medica. 1978. "The Latin American Experience." Chapter 5 of The Effects of Infant and Child Mortality on Fertility, edited by Samuel H. Preston. New York: Academic Press.

Sah, Raaj K. 1991. "The Effects of Child Mortality Changes on Fertility Choice and Parental Welfare." Journal of Political Economy 99 (3): 582-606.

Soares, Rodrigo R. 2003. "Mortality Reductions, Educational Attainment, and Fertility Choice." Unpublished Manuscript, University of Maryland.

van de Walle, Francine. 1986. "Infant Mortality and the European Demographic Transition." Chapter 4 of The Decline of Fertility in Europe: The Revised Proceedings of a Conference on the Princeton European Fertility Project, edited by Ansley J. Coale and Susan Cotts Watkins, 201-233. Princeton: Princeton University Press.

Wolpin, Kenneth I. 1997. "Determinants and Consequences of the Mortality and Health of Infants and Children." Chapter 10 of Handbook of Population and Family Economics Vol. IA, edited by Mark R. Rosenzweig and Oded Stark, 483-557. Amsterdam: Elsevier. 


\section{A Mathematical Appendix}

Proof of Proposition 1: Model A is given by:

$$
\max _{0 \leq b \leq w /(p+q s)}\left\{\frac{(w-(p+q s) b)^{1-\sigma}}{1-\sigma}+\beta(s b)^{\epsilon} V .\right\}
$$

The assumptions on parameter values $(\sigma, \epsilon, \beta \in(0,1), s \in(0,1], p, q \geq 0, w, V, p+q>$ $0)$ guarantee that (4) is strictly concave in $b$ and that an interior optimum exists. The optimal number of births $b(s)$ as a function of the survival probability $s$ is characterized by the first-order condition:

$$
\frac{(p+q s) s^{-\epsilon} b(s)^{1-\epsilon}}{(w-(p+q s) b(s))^{\sigma}}=\beta \epsilon V
$$

which can be written as:

$$
\frac{(p+q s)(s b(s))^{1-\epsilon}}{s^{1-\sigma}(w s-(p+q s) s b(s))^{\sigma}}=\beta \epsilon V
$$

or:

$$
\frac{(p / s+q)^{1-\sigma}(s b(s))^{1-\epsilon}}{(w /(p / s+q)-s b(s))^{\sigma}}=\beta \epsilon V .
$$

There is a unique $b(s)$ which satisfies (6) for any $s$. Notice that the term $(p / s+q)$ is non-increasing in $s$ (strictly decreasing if $p>0)$, while the term $w /(p / s+q)$ is nondecreasing in $s$ (strictly increasing if $p>0)$. Since (6) has to be satisfied for all $s, s b(s)$ is therefore non-decreasing in $s$ (strictly increasing if $p>0$ ), which proves the first part of the claim.

If $p=0$, (5) simplifies to:

$$
\frac{q(s b(s))^{1-\epsilon}}{(w-q s b(s))^{\sigma}}=\beta \epsilon V .
$$

Since $s$ only enters through $s b(s)$, net fertility $s b(s)$ has to be constant for all $s$ to satisfy (7).

Finally, if $q=0$ (5) simplifies to:

$$
\frac{p b(s)^{1-\epsilon}}{s^{\epsilon}(w-p b(s))^{\sigma}}=\beta \epsilon V .
$$

Since the left-hand side is strictly decreasing in $s^{\epsilon}$ and (8) has to be satisfied for all $s$, $b(s)$ is strictly increasing in $s$, which proves the last part of the claim.

Proof of Proposition 2: We are considering Model B under the assumption that the 
per-birth cost is zero, $p=0$. In this case, Model B is a special case of the model analyzed by Sah (1991), and the results derived there apply. Specifically, define:

$$
u(n)=\frac{(w-q n)^{1-\sigma}}{1-\sigma}+\beta n^{\epsilon} V,
$$

and:

$$
U(b, s)=\sum_{n=0}^{b} u(n)\left(\begin{array}{l}
b \\
n
\end{array}\right) s^{n}(1-s)^{b-n} .
$$

The choice problem is to maximize $U(b, s)$ by choice of $b$, and $U(n)$ is strictly concave in $n$ and does not depend on $b$ or $s$. The model is now in the form of Sah (1991), and since the concavity assumption is satisfied, the proof for Proposition 2 in Sah (1991) applies here as well.

To prove Proposition 3, it is useful to first develop some additional notation. The assumptions $p=0$ and $s_{y}=1$ are maintained throughout. Let $V_{t}\left(h_{t}\right)$ be the utility at time $t \leq T$ given that state $h_{t}$ has been realized. These utilities are given by:

$$
V_{T}(n, y)=\frac{(w-q y)^{1-\sigma}}{1-\sigma}+\beta\left[(1-y) n^{\epsilon}+y(n+1)^{\epsilon}\right] V
$$

for $t=T$ and:

$$
\begin{aligned}
V_{t}(n, y)= & \frac{(w-q y)^{1-\sigma}}{1-\sigma}+\gamma b_{t}(n, y) s_{i}\left[(1-y) V_{t+1}(n, 1)+y V_{t+1}(n+1,1)\right] \\
& +\gamma\left(1-b_{t}(n, y) s_{i}\right)\left[(1-y) V_{t+1}(n, 0)+y V_{t+1}(n+1,0)\right]
\end{aligned}
$$

for $0 \leq t \leq T$. Optimal birth decisions are determined by:

$$
\begin{aligned}
& b_{t}(n, y)=\operatorname{argmax}_{b \in\{0,1\}}\left\{b\left[(1-y) V_{t+1}(n, 1)+y V_{t+1}(n+1,1)\right]\right. \\
&\left.+(1-b)\left[(1-y) V_{t+1}(n, 0)+y V_{t+1}(n+1,0)\right]\right\},
\end{aligned}
$$

with the additional restriction that $b_{t}(n, y)=0$ for $t>K$. I assume that when a parent is just indifferent, a birth takes place and $b_{t}(n, y)=1$. This assumption is for ease of exposition only and does not affect results. We will also need to consider derivatives with respect to $s_{i}$. Since the usual derivative may not be well defined for all $s_{i}\left(b_{t}\right.$ is a 
step function), we will use left-hand derivatives. We have $\frac{\partial V_{T}(n, y)}{\partial s_{i}}=0$ and for $t<T$ :

$$
\begin{aligned}
\frac{\partial V_{t}(n, y)}{\partial s_{i}}=\gamma & b_{t}(n, y)\left[V_{t+1}(n+y, 1)-V_{t+1}(n+y, 0)\right] \\
& +\gamma\left[\left(1-b_{t}(n, y) s_{i}\right) \frac{\partial V_{t+1}(n+y, 0)}{\partial s_{i}}+b_{t}(n, y) s_{i} \frac{\partial V_{t+1}(n+y, 1)}{\partial s_{i}}\right] .
\end{aligned}
$$

Notice that (11) and (12) imply:

$$
b_{t}(n, 1)=b_{t}(n+1,0)
$$

and:

$$
\frac{\partial V_{t}(n, 1)}{\partial s_{i}}=\frac{\partial V_{t}(n+1,0)}{\partial s_{i}} .
$$

These relations will be used below. The following lemma can now be established:

Lemma 1 For all $t$ and $y, V_{t}(n, y)$ is strictly monotone increasing and weakly concave in $n$. $b_{t}(n, y)$ is non-increasing in $n . V_{t}(n, 1)-V_{t}(n, 0)$ is non-increasing in $n$.

Proof: First, notice that $V_{t}(n, 1)$ is equal to $V_{t}(n+1,0)$ apart from the first term, which does not depend on $n$. Concavity of $V_{t}(n, 0)$ (i.e., $V_{t}(n+1,0)-V_{t}(n, 0)$ is nonincreasing in $n)$ is therefore equivalent to $V_{t}(n, 1)-V_{t}(n, 0)$ being non-increasing in $n$. The last part of the claim is therefore implied once we prove the first part. We also have:

$$
V_{t}(n, 1)-V_{t}(n-1,1)=V_{t}(n+1,0)-V_{t}(n, 0) .
$$

Monotonicity and concavity of $V_{t}(n, 0)$ therefore imply the same properties for $V_{t}(n, 1)$. In the induction step below, it therefore suffices to establish these properties for $V_{t}(n, 0)$.

The proof proceeds by induction. The first step is to show that $V_{T}(n, y)$ is strictly increasing and concave in $n$. These properties follow directly from the definition (9). Since $T>K$, we also have that $b_{T}(n, y)=0$, thus $b_{T}(n, y)$ is non-increasing in $n$.

Now assume that $V_{t+1}(n, y)$ is strictly increasing and weakly concave in $n$ for $y \in$ $\{0,1\}$. To complete the induction, we need to show that $V_{t}(n, 0)$ has the same properties and that $b_{t}(n, y)$ is non-increasing in $n$. For the last part, it follows from (11) that $b_{t}(n, 0)=1$ if and only if:

$$
V_{t+1}(n, 1)-V_{t+1}(n, 0) \geq 0 \text {. }
$$

Since we assume that $V_{t+1}$ is increasing and concave, the difference on the left-hand side is non-increasing in $n$, and therefore $b_{t}(n, 0)$ is non-increasing in $n$. The same argument applies to $b_{t}(n, 1)$. Next, notice that in $(10) V_{t}(n, 0)$ is a strictly increasing 
function of the $V_{t+1}$ on the right-hand side. Since the $V_{t+1}$ are assumed to be strictly increasing in $n$, raising $n$ therefore strictly increases $V_{t}(n, 0)$ even if the birth decision is held constant. $V_{t}(n, 0)$ is therefore strictly increasing.

Concavity requires more work. We want to show that $V_{t}(n+1,0)-V_{t}(n, 0)$ does not increase with $n$ :

$$
\left[V_{t}(n+1,0)-V_{t}(n, 0)\right]-\left[V_{t}(n, 0)-V_{t}(n-1,0)\right] \leq 0
$$

for all $n$. Three cases can be distinguished. Assume first that for a given $n, b_{t}(n+$ $1,0)=b_{t}(n, 0)=b_{t}(n-1,0)=b$. Writing out (16) for this case gives:

$$
\begin{aligned}
b s_{i}\left[V_{t+1}(n+1,1)-\right. & \left.2 V_{t+1}(n, 1)+V_{t+1}(n-1,1)\right] \\
& +\left(1-b s_{i}\right)\left[V_{t+1}(n+1,0)-2 V_{t+1}(n, 0)+V_{t+1}(n-1,0)\right] \leq 0,
\end{aligned}
$$

which holds because of the assumed concavity of $V_{t+1}$, regardless of $b$. Next, assume $b_{t}(n+1,0)=b_{t}(n, 0)=0$ and $b_{t}(n-1,0)=1$ (notice that we already established that $b_{t}$ is non-increasing in $n$ given the induction hypothesis). In this case, writing out (16) gives:

$$
V_{t+1}(n+1,0)-2 V_{t+1}(n, 0)+\left[s_{i} V_{t+1}(n-1,1)+\left(1-s_{i}\right) V_{t+1}(n-1,0)\right] \leq 0
$$

Notice that since $b_{t}(n, 0)=0$, we must have $V_{t+1}(n, 0)>V_{t+1}(n, 1)$. Since the lefthand side is increased relative to (17), it is therefore sufficient to show:

$$
\begin{aligned}
& V_{t+1}(n+1,0)-V_{t+1}(n, 0) \\
& \quad-\left[s_{i}\left[V_{t+1}(n, 1)-V_{t+1}(n-1,1)\right]+\left(1-s_{i}\right)\left[V_{t+1}(n, 0)-V_{t+1}(n-1,0)\right]\right] \leq 0 .
\end{aligned}
$$

Because of (15), this is equivalent to:

$$
\begin{aligned}
& V_{t+1}(n+1,0)-V_{t+1}(n, 0) \\
& \quad-\left[s_{i}\left[V_{t+1}(n+1,0)-V_{t+1}(n, 0)\right]+\left(1-s_{i}\right)\left[V_{t+1}(n, 0)-V_{t+1}(n-1,0)\right]\right] \leq 0,
\end{aligned}
$$

which is satisfied because of the assumed concavity of $V_{t+1}(n, 0)$. The last case is $b_{t}(n+1,0)=0$ and $b_{t}(n, 0)=b_{t}(n-1,0)=1$. Writing out (16) gives:

$$
\begin{aligned}
V_{t+1}(n+1,0)-2\left[s_{i} V_{t+1}(n, 1)\right. & \left.+\left(1-s_{i}\right) V_{t+1}(n, 0)\right] \\
+ & {\left[s_{i} V_{t+1}(n-1,1)+\left(1-s_{i}\right) V_{t+1}(n-1,0)\right] \leq 0 . }
\end{aligned}
$$

This time, since $b_{t}(n, 0)=1$, we must have $V_{t+1}(n, 0) \leq V_{t+1}(n, 1)$. By the same argument as before, it is sufficient to establish the following condition where the left- 
hand side has is increased relative to (19):

$$
\begin{aligned}
& V_{t+1}(n+1,0)-V_{t+1}(n, 0) \\
& \quad-\left[s_{i}\left[V_{t+1}(n, 1)-V_{t+1}(n-1,1)\right]+\left(1-s_{i}\right)\left[V_{t+1}(n, 0)-V_{t+1}(n-1,0)\right]\right] \leq 0 .
\end{aligned}
$$

This is (18) and therefore satisfied. $V_{t}(n, 0)$ is therefore concave, which completes the proof.

Proof of Proposition 3: We would like to show that $b_{t}(n, y)\left(s_{i}\right)$ is non-increasing in $s_{i}$. From (11), we have that $b_{t}(n, y)\left(s_{i}\right)=1$ if and only if:

$$
V_{t+1}(n+y, 1) \geq V_{t+1}(n+y, 0) \text {. }
$$

It is therefore sufficient to show that for all $t$ and $n$ :

$$
\frac{\partial V_{t}(n, 1)}{\partial s_{i}} \leq \frac{\partial V_{t}(n, 0)}{\partial s_{i}}
$$

The proof is once again by induction. At time $T$, condition (20) is trivially satisfied since $\frac{V_{T}(n, y)}{\partial s_{i}}=0$ for all $n$ and $y$. Now assume that:

$$
\frac{\partial V_{t+1}(n, 1)}{\partial s_{i}} \leq \frac{\partial V_{t+1}(n, 0)}{\partial s_{i}}
$$

is satisfied for all $n$. To complete the proof, we need to show that (20) follows at time $t$ for all $n$. Using (12), condition (20) can be written as:

$$
\begin{aligned}
& \frac{\partial V_{t}(n, 1)}{\partial s_{i}}-\frac{\partial V_{t}(n, 0)}{\partial s_{i}}= \\
& \gamma b_{t}(n, 1)\left[V_{t+1}(n+1,1)-V_{t+1}(n+1,0)\right]-\gamma b_{t}(n, 0)\left[V_{t+1}(n, 1)-V_{t+1}(n, 0)\right] \\
&+\gamma\left[\left(1-b_{t}(n, 1) s_{i}\right) \frac{\partial V_{t+1}(n+1,0)}{\partial s_{i}}+b_{t}(n, 1) s_{i} \frac{\partial V_{t+1}(n+1,1)}{\partial s_{i}}\right] \\
& \quad-\gamma\left[\left(1-b_{t}(n, 0) s_{i}\right) \frac{\partial V_{t+1}(n, 0)}{\partial s_{i}}+b_{t}(n, 0) s_{i} \frac{\partial V_{t+1}(n, 1)}{\partial s_{i}}\right] \leq 0 .
\end{aligned}
$$

The first term is less than or equal to zero since Lemma 1 shows:

$$
V_{t+1}(n+1,1)-V_{t+1}(n+1,0) \leq V_{t+1}(n, 1)-V_{t+1}(n, 0)
$$

and Lemma 1 together with (11) implies that $b_{t}(n, 0) \leq b_{t}(n, 1)$. It therefore suffices 
to show that:

$$
\begin{aligned}
\gamma\left[\left(1-b_{t}(n, 1) s_{i}\right)\right. & \left.\frac{\partial V_{t+1}(n+1,0)}{\partial s_{i}}+b_{t}(n, 1) s_{i} \frac{\partial V_{t+1}(n+1,1)}{\partial s_{i}}\right] \\
& -\gamma\left[\left(1-b_{t}(n, 0) s_{i}\right) \frac{\partial V_{t+1}(n, 0)}{\partial s_{i}}+b_{t}(n, 0) s_{i} \frac{\partial V_{t+1}(n, 1)}{\partial s_{i}}\right]<0 .
\end{aligned}
$$

This condition is satisfied since (14) and the induction hypothesis (21) imply:

$$
\frac{\partial V_{t+1}(n+1,1)}{\partial s_{i}} \leq \frac{\partial V_{t+1}(n+1,0)}{\partial s_{i}}=\frac{\partial V_{t+1}(n, 1)}{\partial s_{i}} \leq \frac{\partial V_{t+1}(n, 0)}{\partial s_{i}}
$$

which completes the proof. 


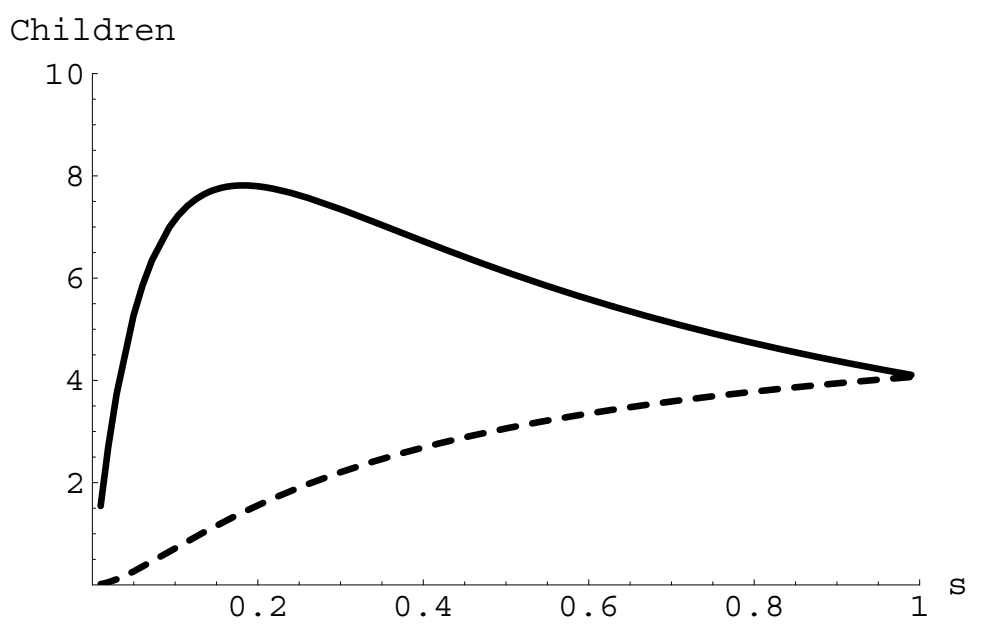

Figure 1: Births and Survivors in the Benchmark Model

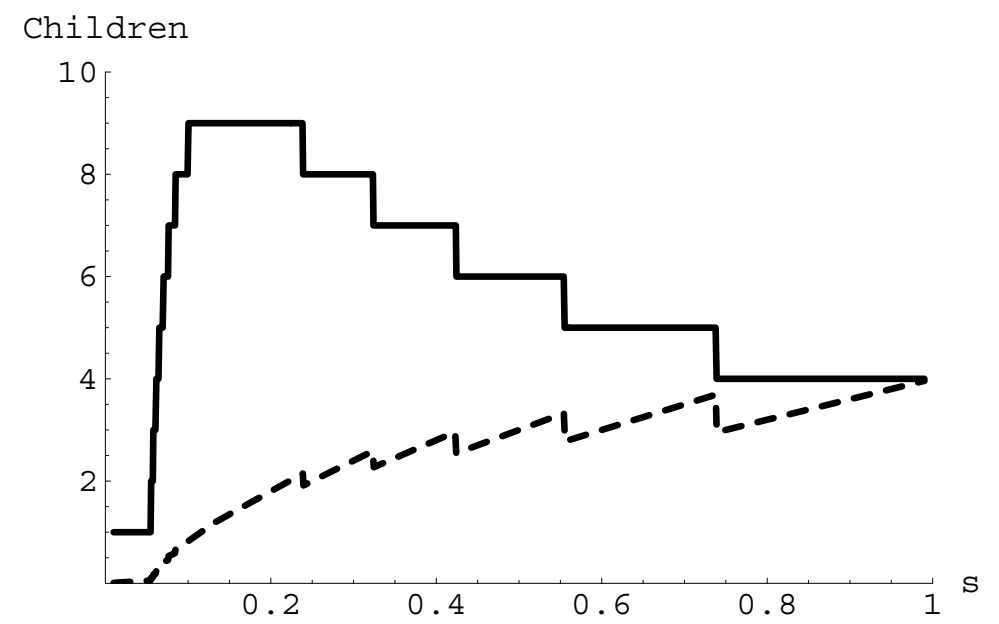

Figure 2: Births and Survivors in the Binomial Model 


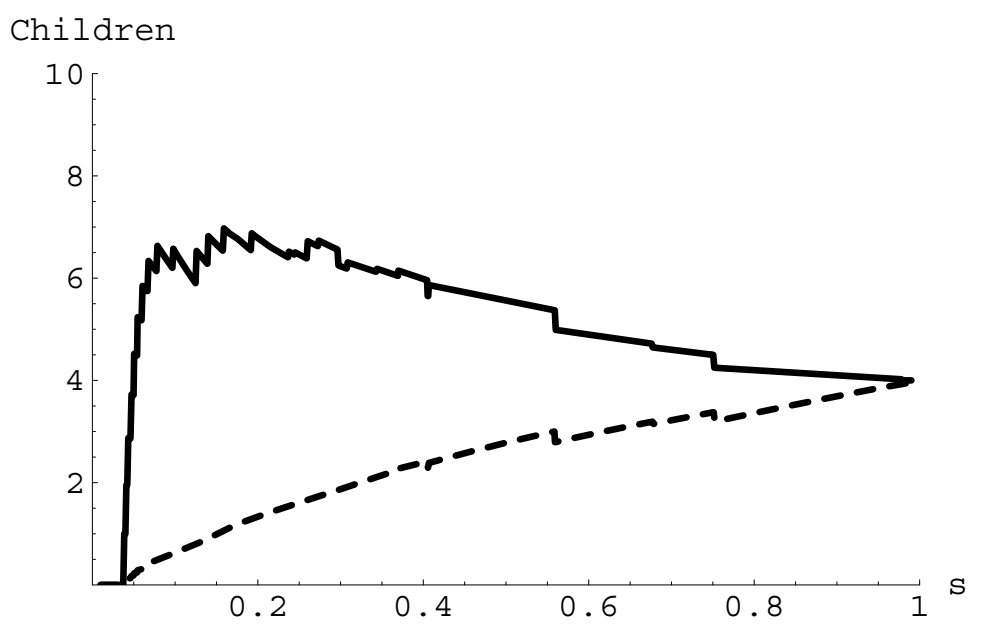

Figure 3: Births and Survivors in the Sequential Model

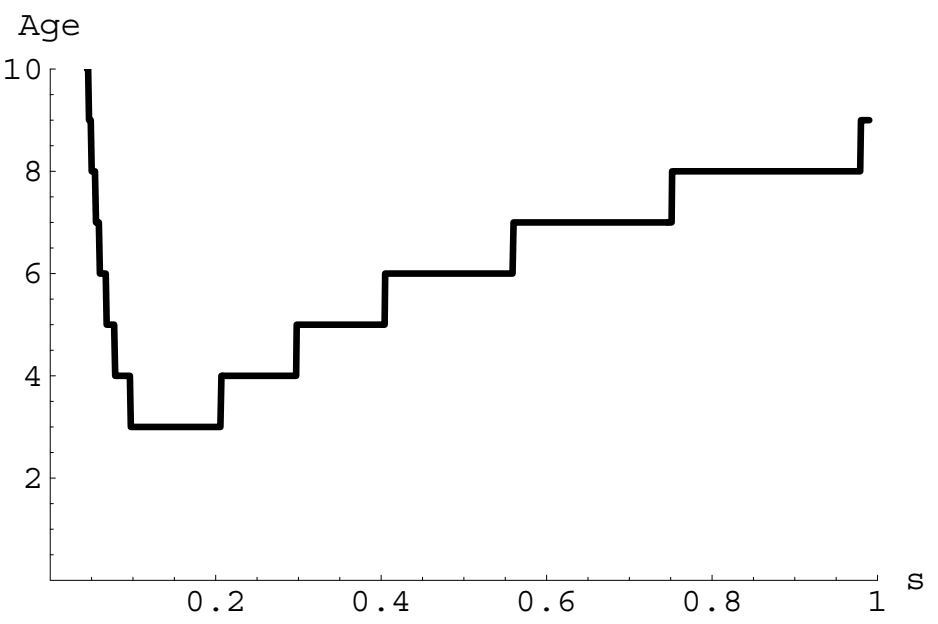

Figure 4: Age at First Birth in the Sequential Model 


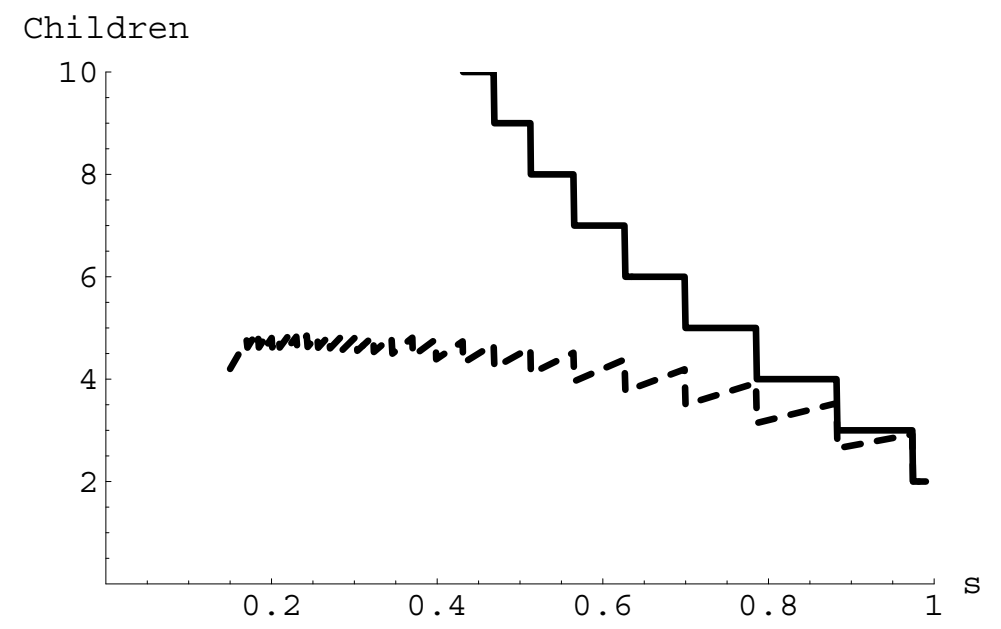

Figure 5: Births and Survivors in the Binomial Model, $\sigma=0.01, \epsilon=0.01$

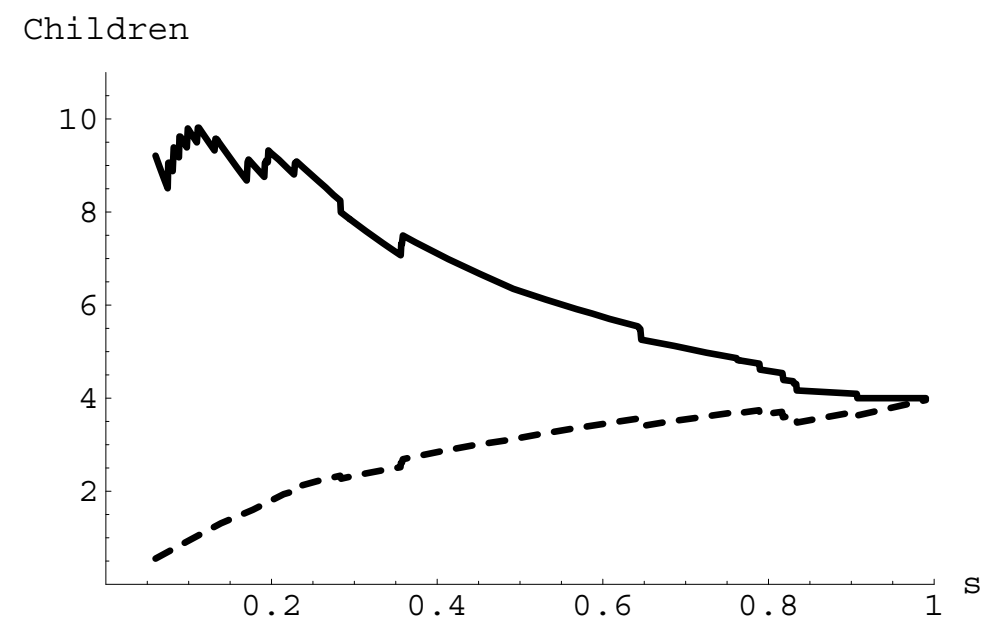

Figure 6: Births and Survivors in the Sequential Model, $\sigma=0.01, \epsilon=0.01$ 


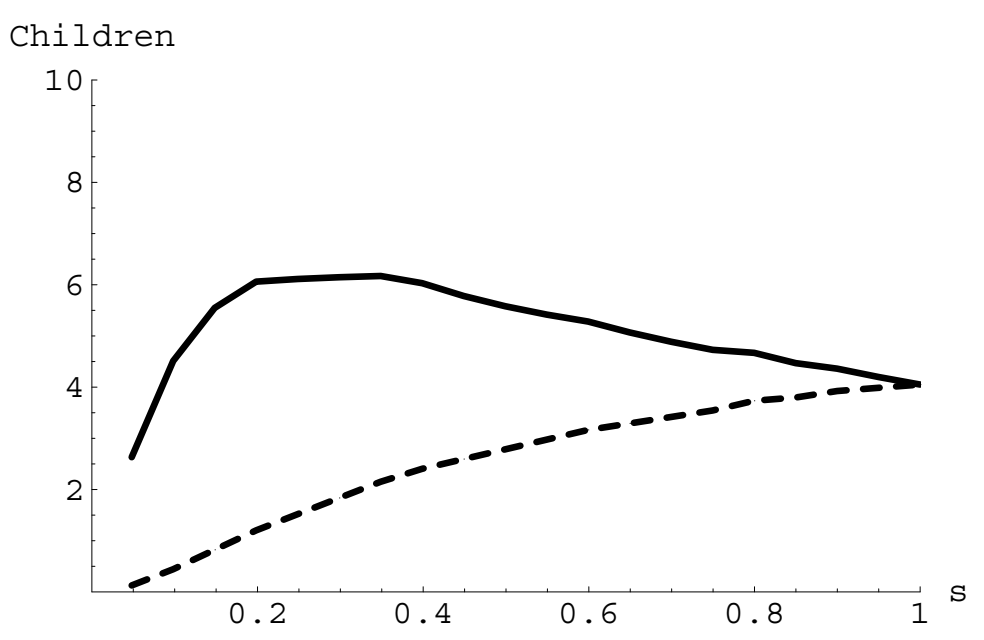

Figure 7: Births and Survivors in the Quantity-Quality Model, 1861 Calibration

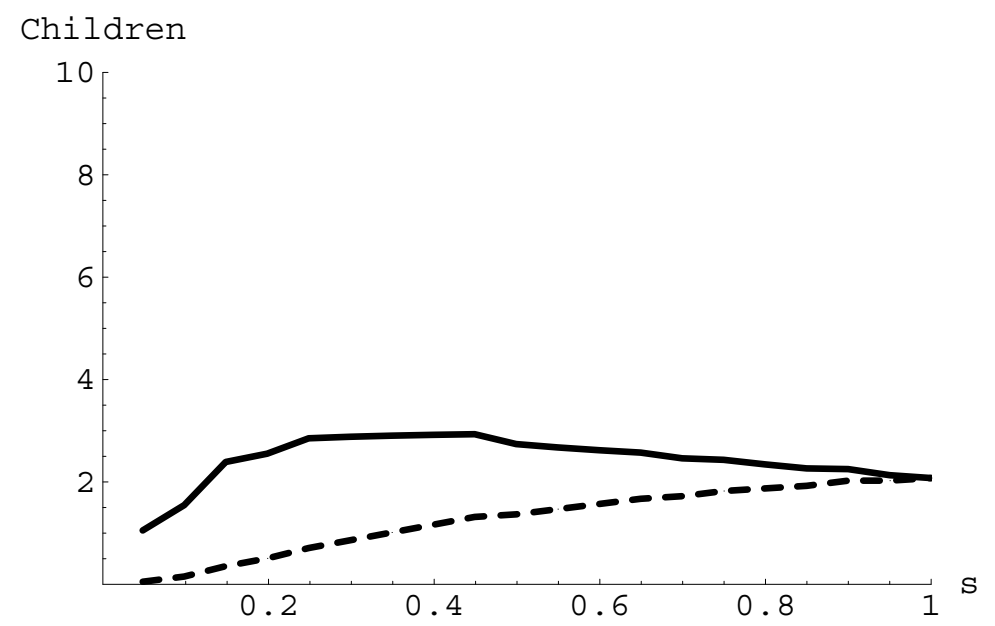

Figure 8: Births and Survivors in the Quantity-Quality Model, 1951 Calibration 


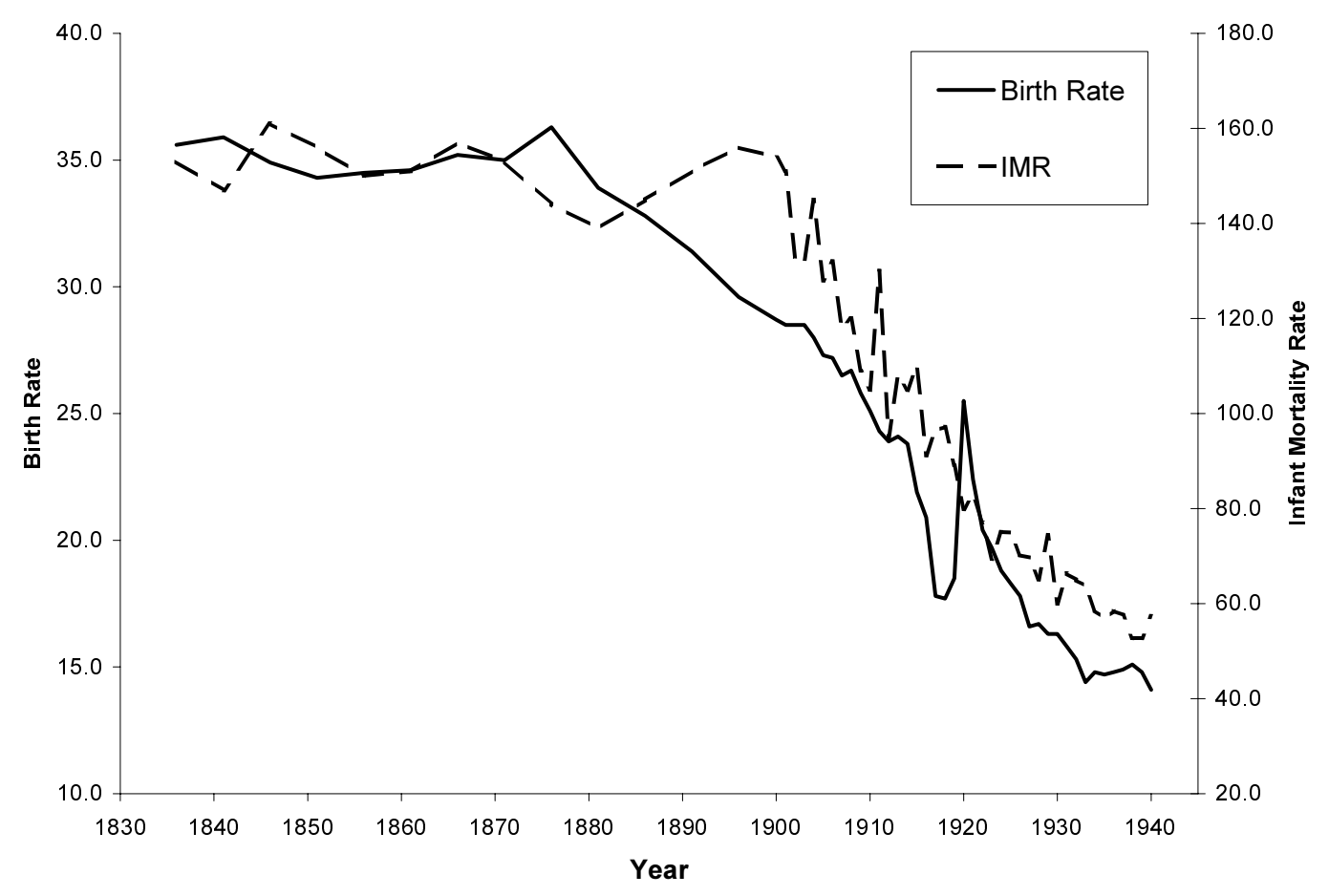

Source: Chesnais (1992).

Figure 9: Birth and Infant Mortality Rates in the United Kingdom

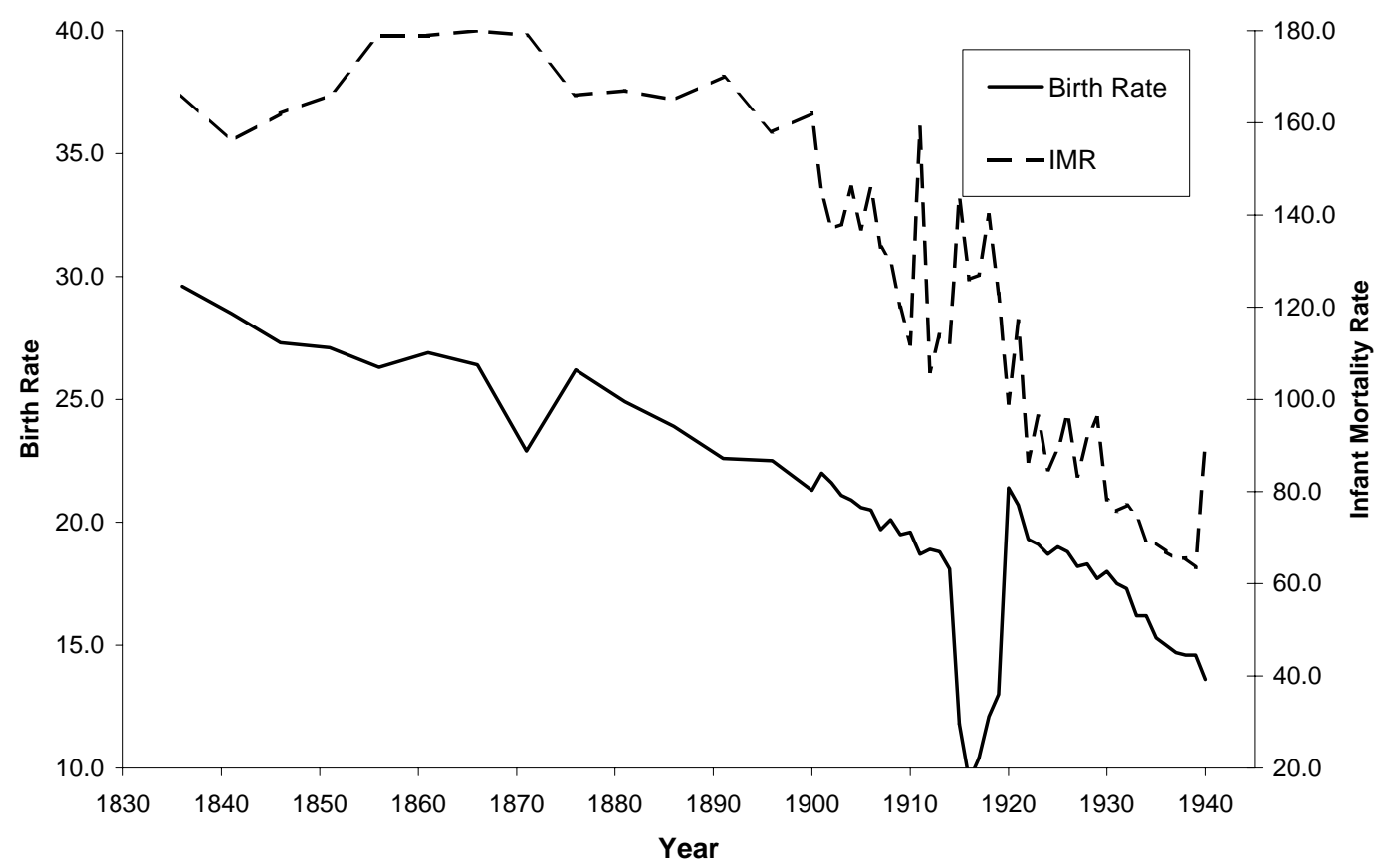

Source: Chesnais (1992).

Figure 10: Birth and Infant Mortality Rates in France 


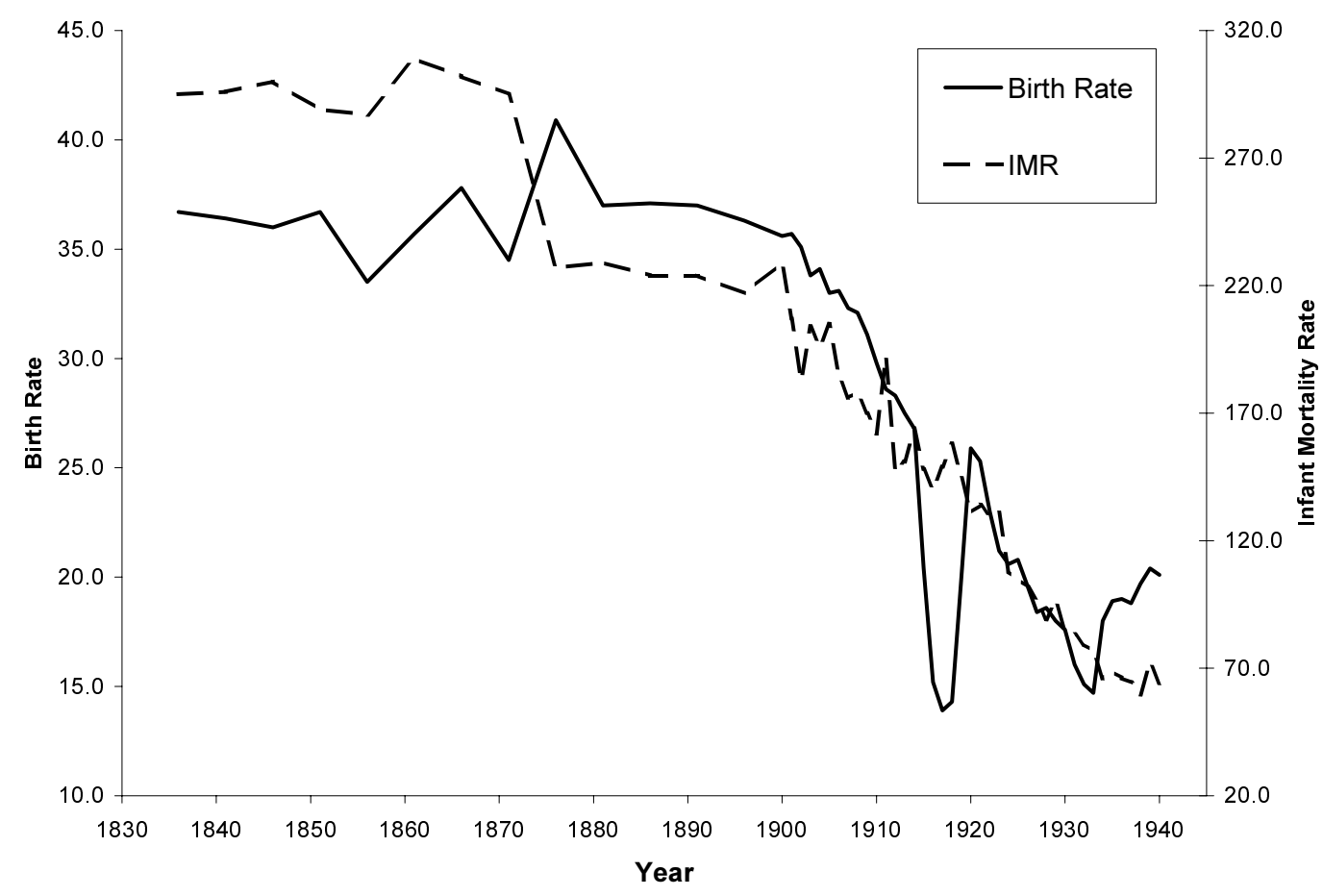

Source: Chesnais (1992).

Figure 11: Birth and Infant Mortality Rates in Germany

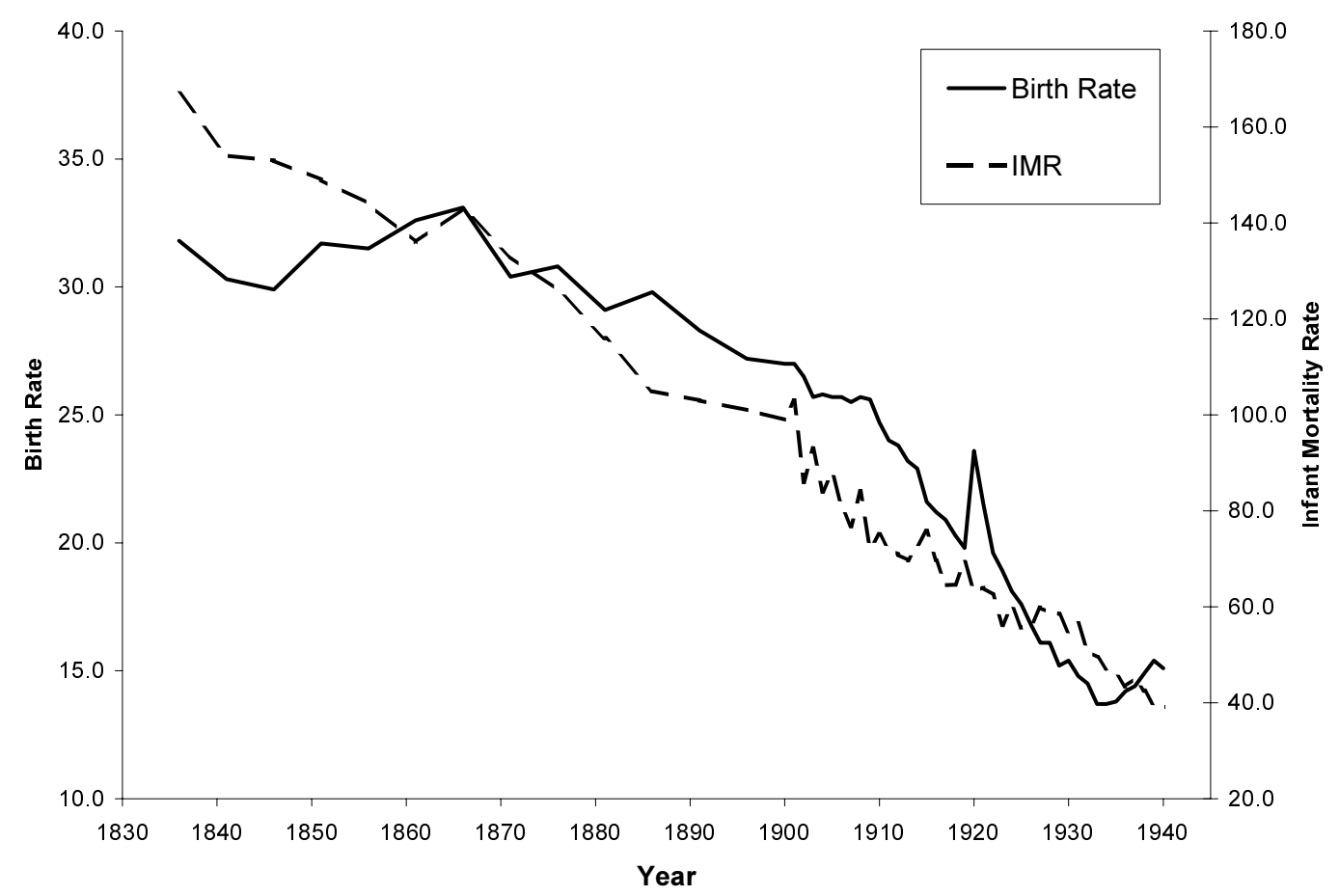

Source: Chesnais (1992).

Figure 12: Birth and Infant Mortality Rates in Sweden 


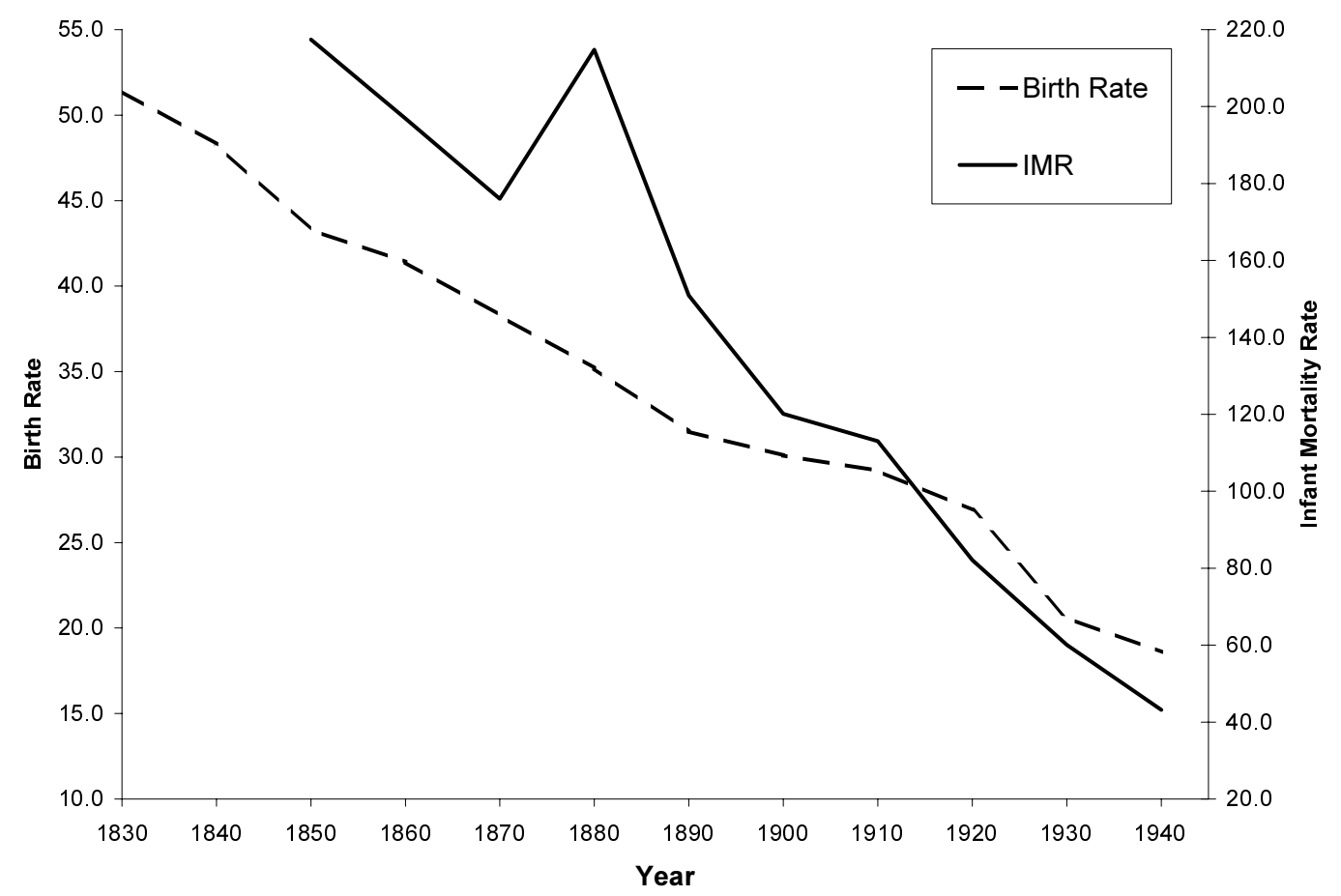

Source: Haines (1998).

Figure 13: Birth and Infant Mortality Rates in the U.S. (White Population) 